Türkiye Jeoloji Bülteni
Geological Bulletin of Turkey
$60(2017) 615-636$
doi:10.25288/tjb.370625

\title{
Yeşilırmak Taraçalarında (Orta Kuzey Anadolu) Geç Pleyistosen İklim Değişiklikleri ve Düşey Yönlü Deformasyona Akarsu Cevabının Araştırılması
}

Investigating the Fluvial Response to Late Pleistocene Climate Changes and Vertical Deformation: Yeşilirmak Terrace Staircases (central north Anatolia)

\author{
M. Korhan Erturaç ${ }^{1, *}$ D, Nafiye Güneç Kıyak ${ }^{2,3}$ (D) \\ ${ }^{1}$ Sakarya Üniversitesi, Coğrafya Bölümü, 54186, Serdivan, Sakarya \\ ${ }^{2}$ Işı \\ ${ }^{3}$ OSLAB Istanbul, Lüminesans Araştırma ve Arkeometri Laboratuvarl, İstanbul
}

Geliş/Received : 29.11.2017 • Düzeltilmiş Metin Geliş/Revised Manuscript Received : 13.12.2017 • Kabul/Accepted : 15.12.2017 • Bask1/Printed : 29.12 .2017 Araştırma Makalesi/Research Article Türkiye Jeol. Bül. / Geol. Bull. Turkey

Öz: Fosilleşmiş taşkın ovası çökelleri olarak da tanımlanan akarsu taraça basamaklanması, akarsuların gelişim süreci üzerindeki iklim, kaide seviyesi ve genç tektonik etkinin analitik olarak belirlenmesi için önemli kayıtlar sunmaktadır. Bu çalışmanın odağında bulunan Yeşilırmak Nehri’nin Çekerek Irmağı ile birleştiği Geldingen Ovası'nın (Amasya) güney kesiminde, her iki akarsuyun kenarlarında bulunan depolanmalı taraça sistemi çalıșılmıștır. Bu taraça sistemi, güncel nehir taşkın ovasından +70 metre üst kotlara kadar ulaşan üç basamaktan oluşmaktadır. Bu basamakların gelişim süreci, farklı seviyelerinden elde edilen toplam 12 adet örneğin lüminesans yöntemi kullanılarak tarihlendirilmesi ile araştırılmıştır.

Elde edilen sonuçlar, taraça seviyelerinin Son Buzul Çağı içerisinde güncel taşkın ovasından T3 (+70), T2 (+35) ve T1(+15) metre göreceli konumlarda, sırasıyla MIS5a, MIS3 ve LGM sonu dönemleri içerisinde depolandığını ortaya koymaktadır. Elde edilen depolanmalı/aşınmalı dönemlerin, Türkiye ve yakın çevresinde gerçekleștirilen iklim değişikliği kayıtları ve Karadeniz seviye değişimleri ile karşılaştırılması, inceleme alanında taraça oluşumunun, son buzul dönemi içerisinde Doğu Akdeniz için tanımlanan yağışl1/kurak dönemlerle uyumlu olduğunu göstermektedir. Her üç taraçanın terkedilme zamanı ve konumu oranlandığında, Kuzey Anadolu Fayı Zonu'nun içbükey sıkışmalı bir büklüm yaptığı orta kesiminde ortalama $0.94 \pm 0.26 \mathrm{~mm} / \mathrm{y} 1$ yükselme hızı hesaplanmaktadır.

Anahtar Kelimeler: Akarsu taraçaları, İklim değişikliği, Kuzey Anadolu Fay Zonu, Optik Uyarmalı Lüminesans (OSL), tektonik yükselme hızı, Yeşilırmak.

Abstract: River terraces are remnants of former river floodplains that are fossilized above present-day river channels, often in staircase systems. The formation of terrace staircases is attributed to both tectonic, climate and sea/base level changes. Variations in tectonic and climatic conditions cause perturbations in the fluvial system, which, over time, lead to widening of valley floors, aggradation and incision, thereby producing terraces representing the complex response of the fluvial system to the chances in variables listed above.

This study reports on the formation of terrace staircases at Yeşilirmak River system of central northwest Anatolia, near Geldingen Plain (Amasya). The depositional steps reaching $+70 \mathrm{~m}$ (above today's recent floodplain), have been mapped and dated by using luminescence method which reveals that terrace formation started at early late Pleistocene and continued within Last Glacial Period. The terrace steps, namely T3 $(+70 \mathrm{~m}), T 2(+35 \mathrm{~m})$ and T1 $(+15)$ were deposited during MIS5a, MIS3 and end of LGM. The correlation with the adjacent climate archives reveals that the terraces are formed primarily in response to climatically induced fluctuations in river discharge and sediment supply. Relative positions of the terrace risers and abandonment ages, enables us to calculate a long-term vertical uplift rate of $0.94 \pm 0.26 \mathrm{~mm} /$ year at the study area, located to the south of the North Anatolian Fault Zone.

Keywords: River Terraces, Climate Change, Optically Stimulated Luminescence (OSL), tectonic uplift rate, Yeşilırmak, North Anatolian Fault Zone 


\section{GíRiş}

Bir bölgenin jeomorfolojik gelişimini kontrol eden temel bileşenler olarak aktif tektonik deformasyonun nitelik ve niceliğinin belirlenmesi ile kısa (bin ve yüz y1l) ve uzun dönem (onbinyüzbin y1l) iklim değişikliklerinin anlaşılması, özellikle Kuvaterner yaşlandırma yöntemlerinin gelişmesi ve yaygınlaşması sayesinde, son yıllarda yerbilimlerinin en popüler araştırma konularından olmuştur. Geçmişte yaşanan iklim değişikliklerinin anlaşılmasının, günümüz ve daha önemlisi gelecek kestirimlerinde başlıca veri kaynaklarını oluşturduğu fikri, konu üzerinde çalışan çok sayıda araştırmacı tarafından ortak paylaşılan bir görüştür (Elias, 2007). Son 50 yıl içerisinde küresel ölçekte gerçekleştirilen önemli çalışmalar sonucu (DSDP, ODP, GRIP programları vb.) elde edilen sekans verileri, ölçme tekniklerinin gelişmesi ve hem küresel hem de yerel iklim salınımlarını hassas olarak yansitan vekillerin (Proxy) artmasiyla, geçmişte buzul çağı olarak tanımlanan dönemler içerisinde de belirgin iklim salınımları olduğu anlaşılmıştır. Böylelikle Kuvaterner Devri stratigrafisinin temelini oluşturan Alpin buzul çağ1 terminolojisi (Würm, Riss, Günz, Mindel vb.) terk edilerek, radyometrik yöntemlerle kesin olarak tarihlenmiş, sınırları olan izotop katları kronolojisine geçilmiştir. Denizel İzotop Katı (MIS) olarak tanımlanan bu stratigrafide çift rakamlar görece soğuk ve kurak tek rakamlar ise 11ıman dönemlere karşıl1k gelmektedir. Geçmişe doğru uzanan kayıtlar değerlendirildikçe bu değişimlerin, 20. yüzyılın başlarında tanımlanan Milankovitch döngüleriyle paralellik gösterdiği anlaşılmıştır. Bunun yanı sıra yer sisteminin bu astronomik çevrimlere cevabı oldukça karmaşıktır. Böylelikle buzul/buzul arası dönemler içerisinde görece 1lıman ve soğuk (interstadial ve stadial) bölümler bulunabilmektedir. Günümüzde geçmiş iklim araştırmalarında temel amaç, bu ana ve ara dönemlere yer sisteminin bileşenlerinin verdiği cevabın anlaşılmasıdır (Elias 2007).

Akarsular, yeryüzünün iç ve diş dinamikleri kontrolünde gelişen ve bu süreçlerin zaman içerisindeki değişimleri/etkilerini yansıtan önemli jeomorfolojik öğelerdir (Bull, 2008; Pazzaglia, 2013). Bir akarsuyun akaçlama havzasından aşındırdığı kırıntılı çökel paketlerinden oluşan taşkın ovasının, akarsuyun kaide seviyesi değişimlerine gösterdiği tepkiye bağlı olarak derine kazarak asılı kalması ile oluşan çökel paketlerine Türkçe literatürde akarsu taraçası, akarsu terası ya da akarsu sekisi adı verilmektedir (Erinç, 1982). Akarsuların akış rejimi ve ilişkili olarak çökel taşıma kapasitesi, nihai kaide seviyesi olan deniz seviyesinin değişimleri (Schumm, 1993) ile yağ $1 s ̧ 11 /$ kurak dönem geçişlerine (Blum and Törnqvist, 2000; Vandenberghe, 2002; Bridgland ve Westaway, 2008; Macklin vd., 2012; Faust ve Wolf, 2017) belirgin bir cevap verir. $\mathrm{Bu}$ cevap, akarsuyun evrimi içerisinde vadi tabanını derinleştirmesi ve genişletmesi, geriye doğru aşındırma hızının artması ile biriktirme ya da aşınma olarak ifade bulmaktadır (Bull, 2008). Özellikle genç ve gençleşen morfojenetik bölgelerde önemli akarsuların ana kolları üzerinde belirgin taraça sistemi (basamaklanması) oluşumu gözlenir (Erinç, 1982; Bull, 2008). Taraçalar morfoloji ve çökel birikimine göre iki sınıfta değerlendirilmektedir. Bunlardan ilki temel ya da bir önceki alüvyal deponun kazılması ile oluşan aşındırmalı (strath) taraçalardır (Bull, 2008). Bu tür taraçalar yer yer görece ince bir çökel örtü içerirler ve akarsu kanalının yanal ve düşey yönde belirgin göçünü ifade ederler. Diğer sınıf ise eski taşkın ovası dolgusunun asılı kalması ile oluşan, bir diğer deyişle kalın ve iyi gelişmiş flüvyal fasiyeslerden oluşan biriktirmeli taraçalardır (Pazzaglia, 2013). Bir akarsu havzası boyunca bu iki ana sinıfa (ve alt siniflara) ait taraçalar depolanma/aşınma dönemlerine karşılık gelmektedirler. Yer şekillerinin oluşum süreçleri içerisinde, özellikle tektonik olarak aktif bölgelerde, akarsuların aşınmalı ve depolanmalı yapıları olarak gelişen taraça sistemleri, düzenli olarak gençleşen bir bölgede bu gençleşmenin kanıtlarını içerisinde barındırmaktadır (Bridgland, 2000; Lave ve Avouac, 2001; Demoulin vd., 2017, 
Olszak, 2017). Taraçaların birbirleri ile mekânsal ve zamansal olarak ilişkilendirilmesi, oluşum kökenleri ve daha önemlisi, geniş anlamda, nedenleri hakkında önemli bilgi kaynağıdır.

Taraça oluşumu bir akarsuyun enerjisindeki değişimlere bağlı olarak gerçekleşir. Jeomorfolojik çevrim içerisinde olgun olarak tanımlanan akarsu sistemlerinde, yerin yörüngesel özelliklerine bağl1 olarak gerçekleşen küresel iklim değişiklikleri (ör: buzul ve buzul arası dönemleri), bölgenin hidrolojik bütçesine ve deniz seviyesinde belirgin değişimlere yol açarak kazılma/biriktirme dönemlerini kontrol eder (Schumm, 1993; Blum and Törnqvist, 2000; Macklin vd., 2012). Özellikle orta Pleyistosen' de gerçekleşen değişim ile 41 bin y1llık yerine, 100 bin y1llık döngülerin egemenliğine geçişle birlikte akarsuların derine kazma hızının arttığ 1 ve akarsuların daha belirgin taraçalar oluşturduğu düşünülmektedir (Bridgland ve Westaway, 2008). Bununla birlikte flüvyal sistemin iklim değişiklerine gösterdiği cevap birden çok etkin bileşene bağlıdır; örneğin akarsuyun akaçlama ağı kapsamında, buzul dönemi içerisinde gerçekleşen yağışlı (aşınmalı) bir dönem, küresel deniz seviyesinin çok düşük olduğunu dönem ile örtüşebilir. Bu gibi durumlar, buzul çağları içerisindeki stadial ve interstadial dönemler nedeniyle halen tartışılmakta olan bir konudur ve akarsu kayıtları önemli yerel iklim değişimleri üzerine değerli bilgiler sunar (Vandenberghe, 2008; Faust ve Wolf, 2017).

Akarsu taraçalarının mutlak tarihlendirilmesi, radyokarbon yönteminin kullanılmaya başlandığı 20. yüzyılın ikinci yarısında başlar. Yöntemin kullanımının artmasıyla özellikle Holosen içerisindeki taşkın ovası ve akarsu kanalı evrimi çalışmaları mutlak tarihlendirme ile birlikte değerlendirilmeye başlamıştır (Blum ve Törnqvist, 2000). Ar/Ar ve K/Ar vb. tarihlendirme yöntemleri, özellikle sürekli volkanizma etkisi altındaki bölgelerdeki akarsu taraça seviyelerini fosilleştiren volkanik malzemenin (lav ve tüf) yaşlandırılarak bu yapıların tarihlendirilmesinde kullanılmıştır (ör: Doğan, 2011; Maddy vd., 2017). Son 20 yıl içerisinde kırıntılı çökellerin dolaysız tarihlendirilmesine yönelik yöntemler geliştirilerek uygulama ve laboratuvar anlamında yaygınlık kazanmıştır (Rixhon vd., 2017). Optik /Kızılötesi Uyarımlı Lüminesans (OSL/IRSL) ve kozmojenik radyonüklid tarihlendirmeleri günümüzde akarsu çökellerinde en yaygın kullanılan Kuvaterner tarihlendirme yöntemleri arasındadır (Wallinga, 2002; Rhodes, 2011, Rixhon vd., 2017).

Yeryüzünde farklı jeolojik ve coğrafik özelliklere sahip önemli nehirlerin üzerine sayıları ve detayları hızla artan çalışmalar ile taraça gelişiminin nedenlerini açıklayan küresel ve bölgesel etkilerin tartışılması mümkün olmuştur. $\mathrm{Bu}$ çalışmalarla taraça oluşumunda birbiriyle çatışan etmenlerin etkileşimleri daha da anlaşılmakta ve klasik soğuk dönem taraça depolanması görüşüne alternatif modeller öne sürülmektedir (tartışmalar ve değerlendirme makaleleri için bakınız: Blum ve Törnqvist, 2000; Bridgeland ve Westaway, 2008; Vandenberghe, 2008; Macklin vd., 2012; Faust ve Wolf, 2017). $\mathrm{Bu}$ etmenlerden küresel etkinliğe sahip olanların başında buzul / buzul arası (ve geçiş) dönemleri gelmektedir (Schumm, 1993; Blum ve Törnqvist, 2000). Buzul çağları boyunca belirgin deniz seviyesi değişimleri, akarsuların kıyıya yakın kesimlerde hızla derine kazmasına yol açmıştır. $\mathrm{Bu}$ etkinin kıyı gerisine doğru uzanımının miktarı, kara ve deniz tabanı morfolojisinde (örneğin akarsu profili ve şelf eğimi) ölçülebilir birçok parametreye bağlıdır ve literatürde iyi tanımlanmış durumdadır (Schumm, 1993; Demoulin vd., 2017). Kronolojik çalışmalar, aktif dağ kuşağı oluşum bölgelerinde taraça gelişiminin, bilinen önemli iklim değişikliklerine karşılık geldiğini ortaya koymakla birlikte, özellikle jeomorfolojik döngü içerisinde olgun olarak tanımlanan, denge profiline ulaşmış ve büyük drenaj alanına sahip akarsularda, taraça gelişimi için sürekli tektonik yükselme bir ön koşul olarak kabul edilmektedir (Pazzaglia, 2013). Flüvyal jeomorfoloji çalışmalarında taraçalar, paleo-jeodezik nirengi noktaları olarak 
değerlendirilmektedir. $\mathrm{Bu}$ yaklaşımın temel çıkış noktası, zamansal ve mekânsal olarak iyi tanımlanmış akarsu taraçalarının güncel taşkın ovası seviyesi ile olan yükseklik farkının, kabuk deformasyonunun sonucu olarak ortaya çıkan yükselim oranını belirlemede kullanılma potansiyelidir (Lave ve Avouac, 2001; Demoulin vd., 2017, Olszak, 2017). Tektonik yükselmenin etkisi, taraça yüksekliğii/ yaş ilişkisi göz önünde alınarak belirlenebilmektedir. Buna göre tektonik aktivitesi yüksek bölgelerde, belirgin yüksekliklere ulaşabilen bir taraça sistematiği Geç Pleyistosen içerisinde gelişebilirken (örn: Himalayalar'da Burbank vd., 1996 ve Doğu Asya'da, Pan vd., 2003) bölgesel ve yavaş bir yükselme gösteren bölgelerde benzer bir sistematiğin oluşması milyon y1l mertebesine yaklaşmaktadır (ör. Paris havzas1 nehirleri: Antoine vd., 2000; Kız1lırmak: Çiner vd., 2015).
Bu çalışmada, Yeşilırmak Nehri ile önemli bir yan kolu olan Çekerek Çayı'nın birleşme noktası olan Geldingen Ovası'nın (Amasya) güney kesiminde yer alan, her iki akarsuyun kenarlarında bulunan depolanmalı taraça sistemi araştırılmıştır. $\mathrm{Bu}$ taraça sistematiği, güncel nehir taşkin ovasından +70 metre üst kotlara kadar ulaşan üç basamak şeklinde bulunur. Bu basamakların, farklı seviyelerinden elde edilen toplam 12 örneğin lüminesans yöntemi ile tarihlendirilmesiyle, taraça oluşumunda etkin olan depolanma (kurak) aşınma (yağışlı) dönemleri tanımlanmış, Doğu Akdeniz ve inceleme alanı yakın çevresindeki (Şekil 1) diğer geçmiş-iklim kayıtlarıyla karşılaştırılması yapılmıştır. Böylelikle taraça basamaklarının göreceli konumları ve yaşları göz önünde bulundurularak bölgenin yükselmesi üzerine bir model sunulmaktadır.

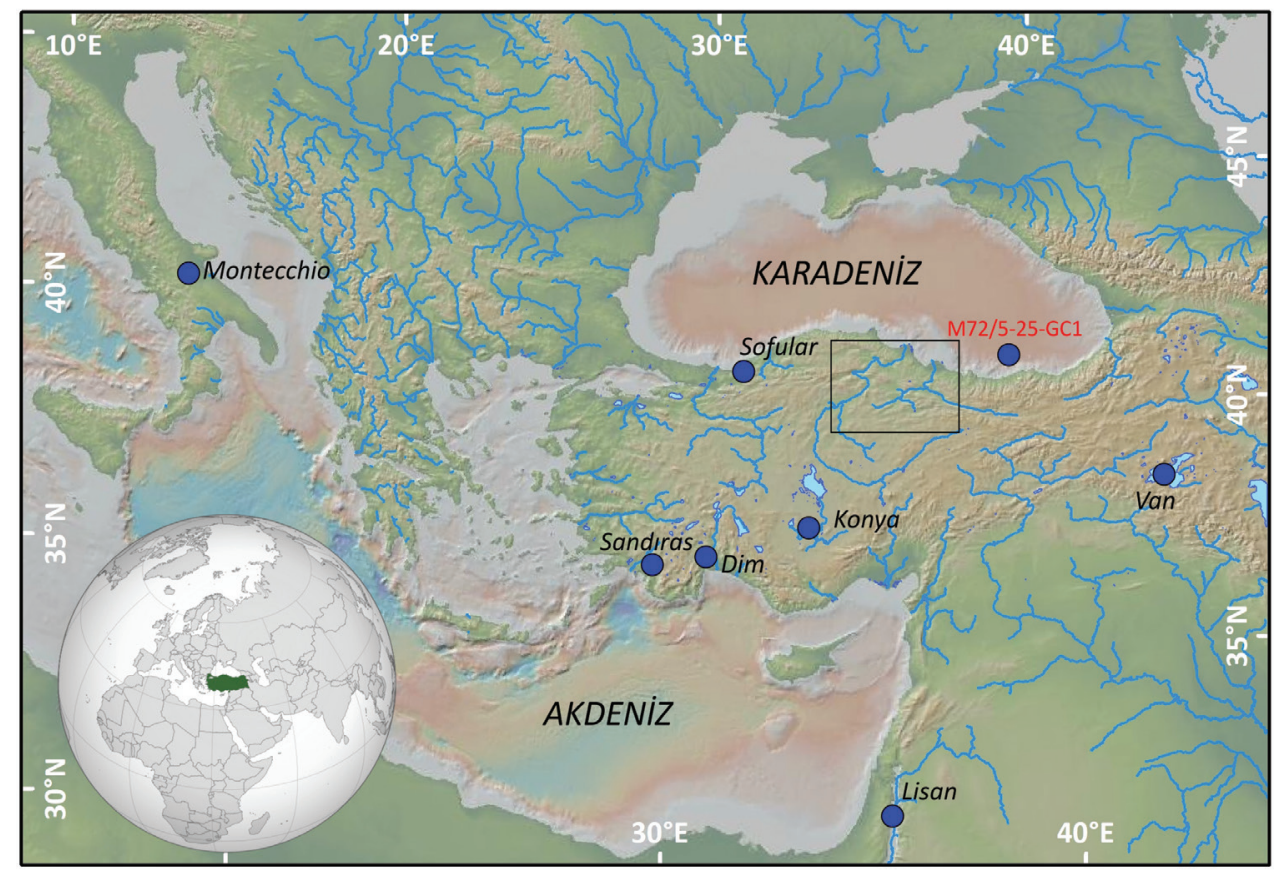

Şekil 1. İnceleme alannın Doğu Akdeniz'in genel fizyografisi içerisindeki konumu. Mavi daireler, bu çalışmada kullanılan iklim kayıtlarının yerlerini göstermektedir. Dikdörtgen Şekil 2'nin kapsamını göstermektedir. Altlık harita GeomapApp programı ile üretilmiştir (Ryan vd., 2009)

Figure 1. Physiography including major rivers of Eastern Mediterranean Region and locations of the paleoclimatic archives referred in this study. Box shows extend of Figure 2. Base map is drawn using GeomapApp software (Ryan et al., 2009). 


\section{INCELEME ALANI}

$\mathrm{Bu}$ çalışmaya konu olan taraça sistematiği Anadolu'nun orta-kuzey kesiminin büyük bir kısmını akaçlayan Yeşilırmak Nehri drenaj alanının orta kesiminde, nehrin Karadeniz'e döküldüğü Çarşamba Deltasına 150 km uzaklıkta yer alır (Şekil 2). Bu bölgede, nehir iki ana koldan oluşur. Bunlardan Yeşilırmak 6300 km², Çekerek (Çorum) Çayı ise $11700 \mathrm{~km}^{2}$ akaçlama alanına sahiptir (Şekil 2). İnceleme alanı, Karasal İç Anadolu (CCAN, Continental Central Anatolia, Türkeş, 1996) olarak, serin yağışlı baharlar ve soğuk yağmurlu kışlar ile tanımlanan yarıkurak step iklimi içerisinde sınıflanmaktadır. Nehirlerin havzaları gözetildiğinde ise ÇekerekÇorum çayları için (622 mm/yıl), Yeşilırmak ise (853 mm/yıl) yıllık ortalama yağış almaktadır (Şekil 2, yağış verisi: Ustaoğlu, 2011). Durucasu istasyonu (Şekil 2) 35 yıllık rasat sonuçlarına göre Yeşilırmak Nehri'nin debisi ortalama $65.4 \mathrm{~m}^{3} / \mathrm{sn}$, taşıdığı çökel yük miktarı ise ortalama 2.866.293 ton/y1l olarak ölçülmüştür (EIE, 2000). İnceleme alanı, Kuzey Anadolu Fayı'nın iç bükey büklüm yaptığı orta kesiminde, ana fay kolundan ayrılan en önemli sentetik yan kol olan D-B doğrultulu Ezinepazar Fayı ve KD-GB doğrultulu Sungurlu Fayları arasındaki keskin $\left(\sim 45^{\circ}\right)$ geçiş bölgesinde yer alır (Barka ve Kadinsky-Cade, 1988; Şekil 2). Sağ yönlü doğrultu atımlı bir makaslama zonu olan Ezinepazar Fayı'nın (Erturaç ve Tüysüz, 2012) farkl1 geometrilerdeki segmentleri kontrolünde yüksek ve çizgisel uzanan dağların arasında gelişen Geldingen Ovası, 380 m ortalama yüksekliğe sahip geniş bir düzlük morfolojisine sahiptir. Ovanın aktif olarak çöken orta-kuzey kısmı, en çok 200 m çökel kalınlığına sahiptir (Karaalioğlu, 1983; Erturaç ve Tüysüz, 2012) ve aynı zamanda Yeşilırmak Nehri’nin birçok yan kolunun (Yeşilırmak, Çekerek ve Deliçay) birleşme yeri özelliğindedir (Şekil 2). Bölgede Triyas yaşlı Yeşilırmak metamorfikleri (fillat ve mermer blokları), Geç Eosen yaşlı ortaç-bazik volkanitler ile nummulitli kireçtaşları temel kayaçları (Tüysüz, 1992 ve 1996) oluşturur. Ova'nın özellikle batı kesiminde geç Miyosenerken Pliyosen yaşlı Geldingen formasyonu (Erturaç ve Tüysüz, 2012) farklı fasiyeslerde akarsu kırıntılarından oluşmaktadır ve özellikle tane litolojisi ile güncel taraça çökellerinden ayrılır (Şekil 3).

$\mathrm{Bu}$ çalışmada ayrıntılandırılan taraça basamaklanması, Geldingen Ovası'nın güneyinde, akarsuların oluşturduğu Bektemur ve Şahinkaya boğazlarının ve Terziköy vadisinin iki yakasında gözlenmektedir (Şekil 3).

\section{Metodoloji}

\section{Haritalama}

İnceleme alanında yer alan, farklı konum ve yüksekliklere sahip taraça basamaklanması, 1/25.000 ölçekli topografik haritalar (Çorum G-35 c4, d3, d4 ve H35 a1 ve a2 paftalar1), 10 m çözünürlükteki sayısal yükseklik modeli (DEM), 1/15.000 ölçekli hava fotoğrafları (1992) ve arazi çalışmaları yardımıyla haritalanmıştır. Taraçaların taban ve tavan konumları, GPS cihazı yardımıyla sürekli ölçüm ile elde edilen noktasal verilerin DEM ile karşılaştırılması ile $\pm 5 \mathrm{~m}$ hassasiyetle belirlenmiştir. Taraçaların tavan -ve gözlenmesi halinde taban seviyesinin- yüksekliği ilişkili akarsuya en yakın olduğu kesimdeki taşkın ovasının ortalama yüksekliğinden çıkarılarak göreceli yükseklik olarak hesaplanmıştır. Taraçalarda açılmış doğal ve yapay yüzlekler incelenerek çökel fasiyesler ve depolanma ortamları tanımlanmıştır. 


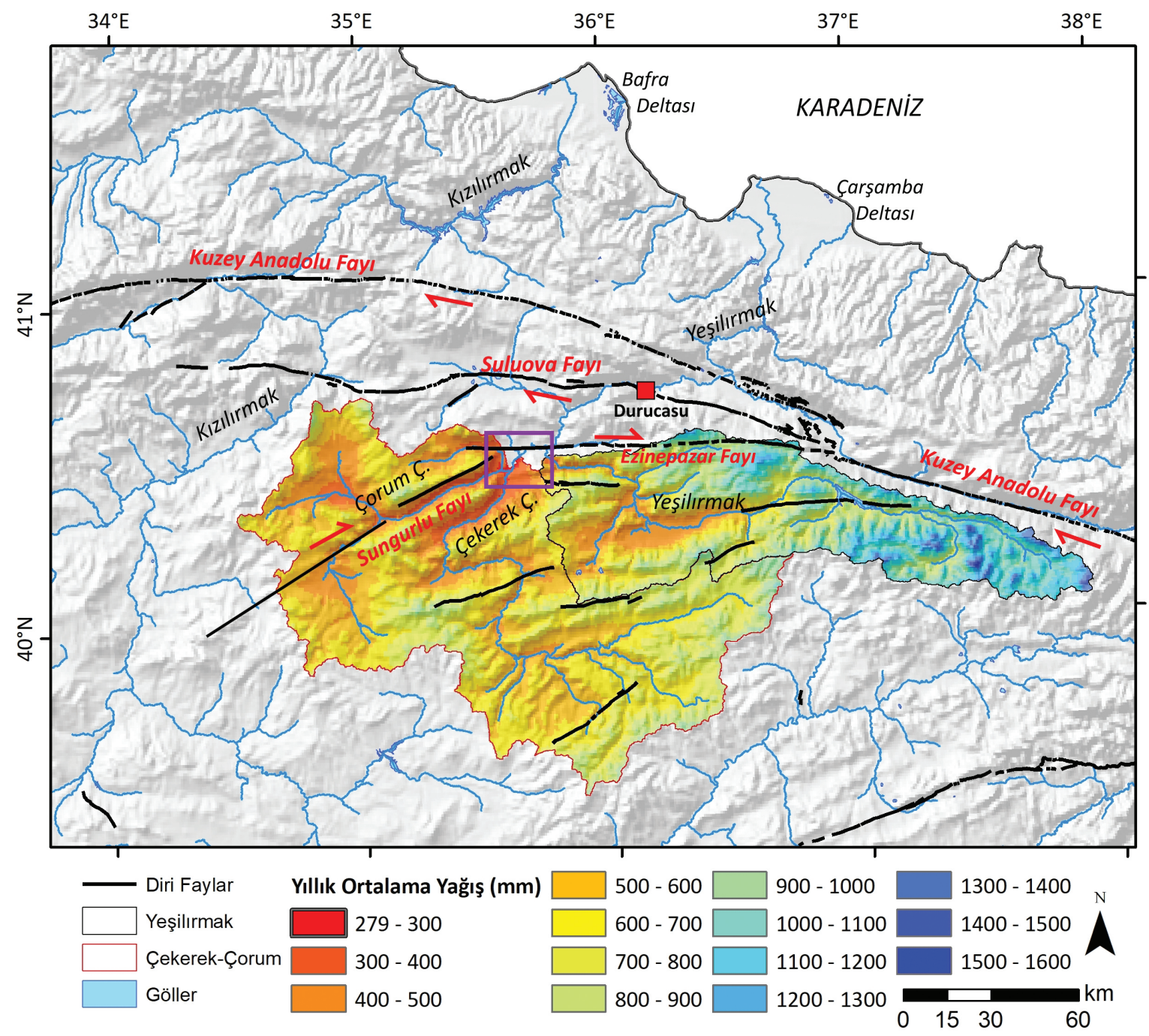

Şekil 2. İnceleme alanda, diri faylar, Yeşilırmak ve Çekerek-Çorum Çayları'nın akaçlama alanları ile Durucasu istasyonunun konumu ve yıllık yağış ortalaması dağılımı (Ustaoğlu, 2011). Mor kutu taraçaların konumlarını göstermektedir (Şekil 3).

Figure 2. Active faults, drainage basins, position of Durucasu station and distribution of mean annual precipitation for Yeşilırmak and Çekerek (Çorum) Rivers (precipitation model from Ustaoğlu, 2011). Purple box represents the location of terraces (Figure 3).

\section{Optik Uyarımlı Lüminesans (OSL) tarihlendirme yöntemi}

$\mathrm{Bu}$ çalışmada taraçaların tarihlendirilmesi, inorganik çökeller kullanılarak Optik Uyarımlı Lüminesans (OSL) yöntemi ile yürütülmüştür. OSL tarihlendirme, çökel tanelerin içerisindeki lüminesans sinyalinin ölçülmesi olarak tanımlanabilir (Aitken, 1998), Yaygın silikat mineralleri olan kuvars ve potasyum feldispat kristalleri içerisinde, mineralin oluşumu ve sonrasinda da iyonize edici radyasyona maruz kalmasıyla, kafes yük yapısında bozulmalar gerçekleşir. Bu kafes yapıda oluşan bozukluklar yapıları, çeşitli derinlik tuzaklarında elektron saklamaya olanak vermektedir. $\sim 1.3$ ile $3 \mathrm{meV}$ 
bandında biriken elektronlar zaman bileşenine bağl1 ölçülebilir lüminesans emisyonlarının kaynağıdır. Mineral kafesi içerisinde ve minerali kuşatan malzeme içinde radyoaktif bozulma gösteren ${ }^{235} \mathrm{U},{ }^{238} \mathrm{U}$ ve ${ }^{232} \mathrm{Th}$ elementleri, radyoaktif özelliğe sahip, ${ }^{40} \mathrm{~K}$ izotopu ve daha düşük oranda da olsa ${ }^{85} \mathrm{Rb}$ ile kozmik kaynaklarından yayılan radyasyon ile serbest elektronlar üretilir. ${ }^{40} \mathrm{~K}$ izotopunun radyoaktif bozulmas U ve Th elementleri de alfa ve bir miktar da beta ve gamma 1şınımı yayar (Aitken, 1998,
Duller, 2008; Forman, 2015). Mineraller aşınma ve taşınma süresince gün 1şı̆̆ına maruz kalarak mineral yapıdaki elektron tuzaklarını saniyeler mertebesinde boşaltır. Depolanma ve gömülme sonrası kristaller içerisindeki lüminesans tuzakları yeniden çevre radyasyonu etkisiyle elektronla dolmaya başlar ve lüminesans saati başlamış olur. Işı̆̆a maruz bırakmadan dikkatli bir örneklemeden sonra, tarihlendirme amaciyla laboratuvar ortamında mineral ayıklama, ölçüm ve değerlendirme aşamaları başlar (Duller, 2008).

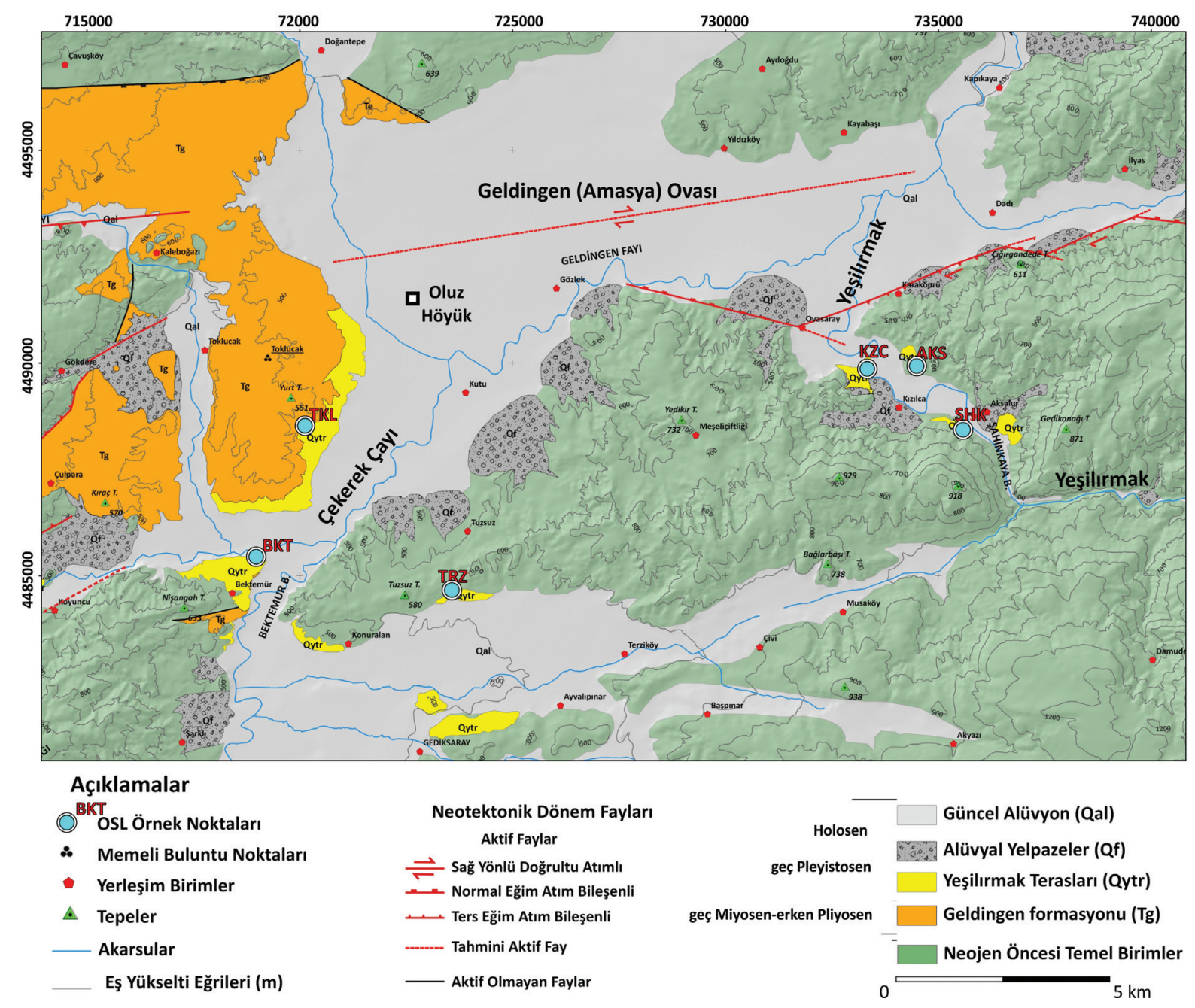

Şekil 3. İnceleme alanının Kuvaterner jeoloji haritası, diri fayları ve taraçaların konumları. Neojen öncesi temel birimler yeşil renkle gösterilmiştir. Yükseklik kontur aralığı 100 metredir (Erturaç ve Tüysüz, 2012'den düzenlenerek).

Figure 3. Quaternary geology map and active faults of the study area and location of the terraces. Pre-Neogene basement is represented with dark green shade (modified after Erturaç and Tüysüz, 2012). 


\section{Örnekleme}

Çalışma kapsamında hedef taraça seviyeleri içerisinde depolanmanın başlangıcı ve sonunu ifade eden tarihler elde edebilmek için, akarsu çökelleri içerisinden ince taneli fasiyesler (taşkın ovası ve kum barları) örneklenmiştir. Örnekleme $7.5 \mathrm{~cm}$ çapında ve $20 \mathrm{~cm}$ uzunluğunda PVC ve çelik karotların temizlenmiş kesit yüzeyine çakılması ile gerçekleştirilmiştir. Örnekleme yerinin yükseklik, yüzeyden derinlik bilgileri not edildikten sonra, karotlar kesitten alınarak alüminyum folyo ile sıkıştırılmış ve 1ş1k geçirmez poşet ve bant ile gün 1şığından izole edilmiştir. Çalışma kapsamında, T1 taraça seviyesinden (3), T2 seviyesinden (6), T2 seviyesini örten lös çökelinden(1), T3 seviyesinden (2), olmak üzere toplam 12 örnek OSL yöntemi ile tarihlendirilmiştir.

\section{Tarihlendirme}

Bu çalışmada, OSL tarihlendirmenin tüm aşamaları (mineral ayıklama ve eşdeğer doz ölçümleri) Işık Üniversitesi, Lüminesans Araştırma ve Arkeometri Laboratuvarı'nda yürütülmüştür. Kullanılan yöntemlerin teknik detayları Kıyak ve Erturaç (2008) çalışmasında detaylı olarak sunulmaktadır.

Mineral ayıklama işlemleri, karot içerisinde örneklenen ince taneli kırıntılılardan kuvars kristallerinin ayrilması amaciyla karanlık odada kırmızı 1şık altında yürütülmektedir. Mineral topluluğu, önce 1slak eleme yöntemi ile 90$180 \mu \mathrm{m}$ aralığına elenir. Ardından karbonatların ayrıştırılması için \%10 derişimli $\mathrm{HCl}$, organiklerin uzaklaştırılması için \%10 derişimli $\mathrm{H}_{2} \mathrm{O}_{2}$ ile işleme tabii tutulur. Manyetik mineraller, mıknatıs ile uzaklaştırılır. Kalan çökel, ağır sıvıda (sodium-polytungstate, 2.62, 2.7 ve $2.58 \mathrm{~g} / \mathrm{cm}^{3}$ ) yüzdürülerek sırasıyla kuvars, ağır mineral ve K-feldispat bileşenlerine ayrilır. Kalan kuvars topluluğu 40 dakika HF (\%40) solüsyonu içerisinde bekletilerek minerallerin diş $\sim 10 \mu \mathrm{m}$ kısmının ve olası kalıntı minerallerin eritilmesi sağlanarak saflaştırılır.

Eşdeğer doz (De) ölçümleri, laboratuvarda bulunan Risø TL/OSL DA-15 model sayıcının SAR protokolü (Murray ve Wintle, 2003) ile programlanması ile yürütülmüştür. $\mathrm{Bu}$ protokol, kuvars kristal topluluklarının yerleştirildiği çelik disklerin, ön 1sıtmalar sonrası k1zılötesi ve mavi 1şı altında uyarılması, U-340 filtre ile lüminesans sinyalinin ölçülmesi ve doz cevap eğrisinin oluşturulmas1 için ${ }^{90} \mathrm{Sr} /{ }^{90} \mathrm{Y} \quad(0.1 \mathrm{~Gy} / \mathrm{s})$ beta radyasyon kaynağı ile dozlanması aşamalarından oluşmaktadır. Şekil 4 A'da çeşitli örneklerin artan radyasyon dozuna verdiği cevabın (lüminesans sinyali) eksponansiyel karakterdeki artış eğrisi sunulmaktadır (Kıyak ve Erturaç, 2008). Bu eğri üzerine ilk aşamada ölçülen doğal sinyal $\mathrm{Lx} / \mathrm{Tx}$ oranına göre yerleştirilerek eş değer doz (De, Gray) hesaplanmaktadır. Şekil 4 B'de KZC-02 örneğinden 10 diske ait De ölçümlerinin radyal dağılımı gösterilmektedir. Bu gösterim yöntemi, ölçümlerin merkezi yaş modeline (CAM, Galbraith ve Roberts, 2012) uygunlukta düşük saçılmaya (\%6) sahip olduğunu ortaya koyar.

Lüminesans yaş denkleminin bir diğer önemli bileşeni olan y1llık çevre dozu oranı (Dr) ölçümleri, arazide taşınabilir gamma spektrometre (Target identiFINDER modeli) ile gerçekleştirilmiştir. $\mathrm{Bu}$ cihaz, örnekleme yerinde 7200 saniye sürekli ölçümle U, Th ve K elementlerinin gamma 1şımasını kaydetmektedir. Ölçümler, daha sonrasında diğer parametrelerle birlikte (nemlilik, yüzeyden derinlik, konum ve yükseklik) Dr hesaplamasında kullanılmaktadır. 

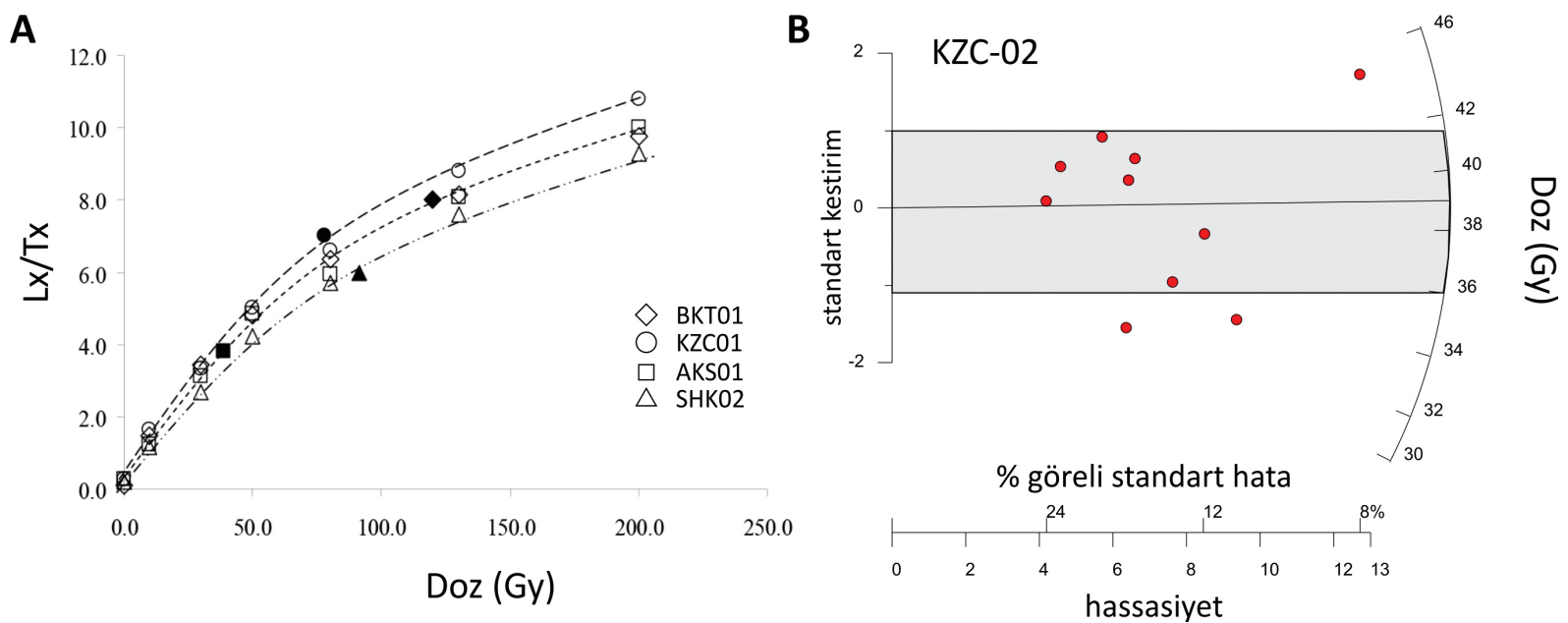

Şekil 4. A. Tarihlendirilen çeşitli örneklerin artan yapay radyasyon altında gösterdiği doz/cevap (büyüme) eğrisi (Kıyak ve Erturaç, 2008'den düzenlenerek). B. KZC-02 örneğinde 10 diskten ölçülen eşdeğer doz dağılımlarının radyal gösterimi.

Figure 4. A. Dose/response curves of different samples under increasing beta radiation exposure (Kiyak and Erturaç, 2008) B. Radial plot of De distribution of KZC-02 sample measured from 10 aliquots.

\section{SONUÇLAR}

\section{Yeşilırmak Taraça Basamaklanması}

Yeşilırmak boyunca Şahinkaya Boğazı ile Geldingen Ovası arasında kalan alanda gözlenen taraça basamaklanması (Şekil 3), kum işletmeleri ve yol yarmaları ile belirgin kesitler oluşturan yüzleklerde gözlenmektedir. Bu kesitler Kızılca (KZC, T1), Aksalur (AKS, T2) ve Şahinkaya (SHK, T2) olarak isimlendirilmiştir. Şekil 5'de bu kesitlere ait arazi görünümleri sunulmaktadır. Basamaklanma içerisinde T2 seviyesi, nehrin doğu yakasında yer alan Aksalur kesitinde, tabanda Yeşilırmak metamorfitleri (TRy) üzerine uyumsuz olarak +15 m göreceli yüksekte yerleşmektedir (Şekil 5A). Kum ocağ1 olarak işletilen kesit, toplam 20 metre kalınlığı boyunca tamamen kaba taneli kanal çökelleri ve aralarda da kum barı fasiyeslerinden oluşmaktadır (Şekil 5B). AKS-1 örneği tabana en yakın kum barından elde edilmiştir. Kesitin en üst kısmında 2 m kalınlığında, tabakalanma göstermeyen silt seviyesi bulunmaktadır. Bu seviye lös çökeli olarak yorumlanmış ve AKS-2 örneği bu seviyeden örneklenmiştir. Bu taraça seviyesinin eşleniği nehrin batı kesiminde Şahinkaya kesitinde de bulunmaktadır. Taraça tabanının gözlenmediği 2 m yüksekliğindeki bu yol yarması, ince tabakalı, yer yer laminalı siltli ince kum seviyelerinden oluşur (Şekil 5C). Bu seviye, fasiyes özellikleri ve konumu ile (+33 m) T2 taraçasının tavan seviyesi olarak yorumlanmıştır. Kızılca kesiti kum ocağ 1 olarak işletilmektedir, tabanı gözlenmemekle birlikte $\sim 8 \quad \mathrm{~m}$ gözlenebilir kalınlığa sahiptir. Kesit tabanda $\sim 5 \mathrm{~m}$ kalınlığında yatak yükü çökellerinden oluşmaktadır, üste doğru tekne çapraz tabakalı nokta barı çökelleri izlenir (Şekil 5D). Kanal çakı1ları içerisinde gözlenen köşeli ince kum bloğu (*), olasılıkla taşkın ovasından koparak kanala taşınmış ve hızla depolanmıştır (Şekil 5D). Bloğun dağılmamasının nedeni büyük ihtimalle aşındığı esnada donmuş olmasıdır. Bu gözlem, taraça oluşum sürecindeki hava sıcaklığı hakkında fikir vermektedir. Bu kesitten elde edilen 3 adet OSL örneği, üst kesimlerdeki yatay tabakal1, siltli ince kumlu taşkın ovası fasiyesinden alınmıştır (Şekil 5D). Taraçanın tavan seviyesinin yüksekliği +10 metredir. 

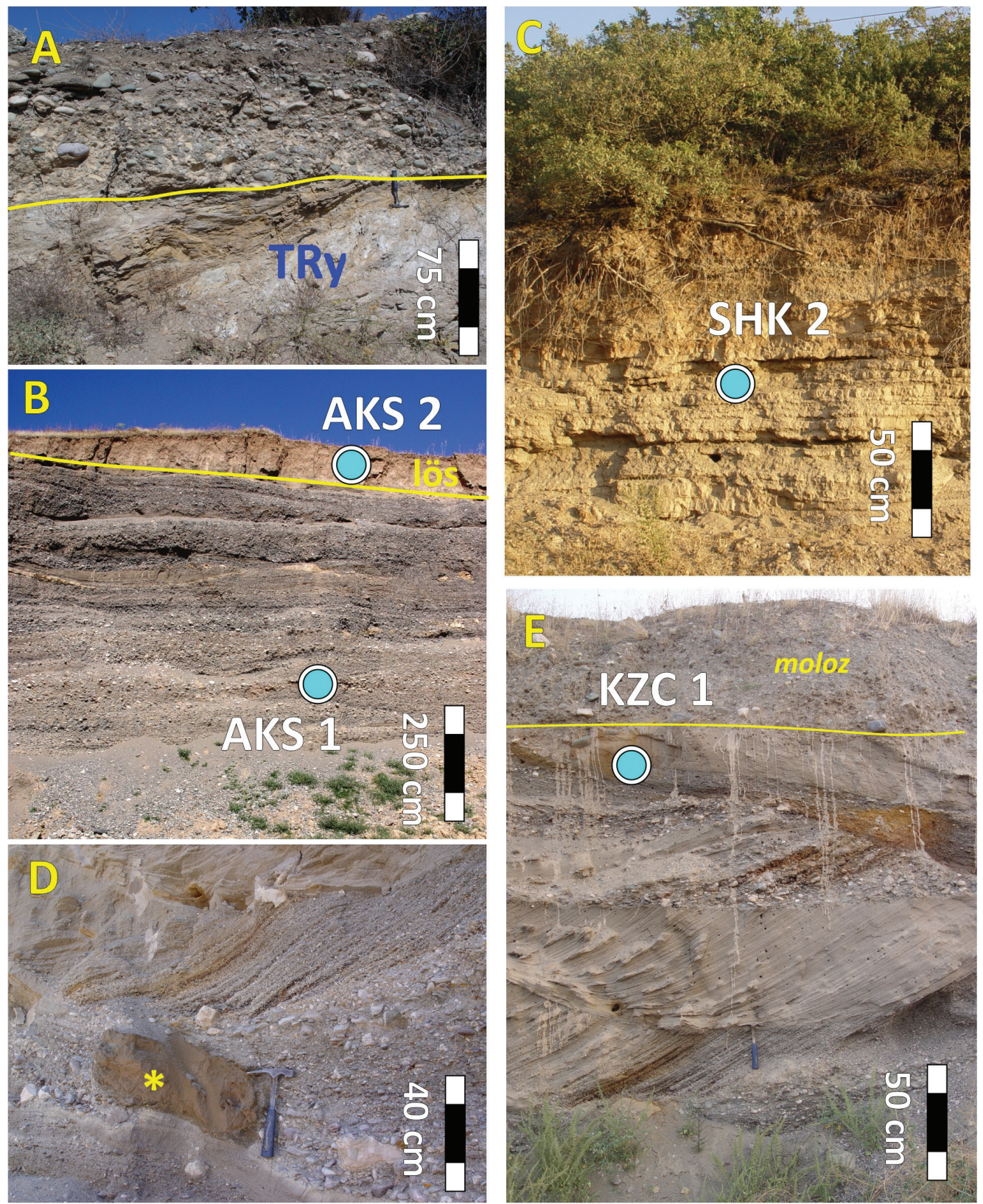

Şekil 5. Yeşilırmak Nehri taraça sisteminin farklı seviyelerinin arazi görünümü. Mavi daireler OSL örnek yerlerine karşılık gelmektedir. A. Aksalur kesitinde T2 taraçasının Triyas yaşı ıeşilırmak metamorfitleri ile dokanağı, B. T2 taraçasının kanal çökelleri, kum barı ara seviyeleri ve bu seviyeyi üzerleyen lös deposu, C. Şahinkaya kesitinde, T2 taraçası tavan kesimini ifade eden ince siltli ince kum (taşkın ovası) tabakalaşması, D Kızılca kesiti tabanında T1 taraçasının kanal çökelleri içerisinde donmuş kum küpü (*), E. Kızılca kesiti çapraz tabakalı nokta kum setleri

Figure 5. Field view from different levels of the Yeşillrmak River terrace staircases. Blue circles represent OSL sample locations A. The contact between channel gravels of T2 terrace and the Yeşilirmak metamorphics of Triassic age at the Aksalur section B. Bedload deposits intercalated with sand bars of T2 terrace, overlain with loess deposits at the Aksalur section. C. Floodplain deposits representing the top of T2 terrace at the Şahinkaya section, D. Channel gravels of $T 1$ terrace at the Kizllca section, * donates a frozen sandy block, E. Cross bedded point bar deposits at the Kizllca section. 


\section{Çekerek Taraça Basamaklanması}

Çekerek Çayı ve yakın çevresinde taraça basamaklanması nehrin batısında ve yakın yan kolu olan Terziköy Deresi'nin sağ ve sol yakalarında gözlenmektedir. Terziköy kesiti (TRZ), 528 metre yüksekliğe sahiptir, derenin güncel seviyesinden göreceli yüksekliği ise +70 m olarak hesaplanmıştır. $\mathrm{Bu}$ taraça, Terziköy Deresi'nin kaide seviyesi olan Çekerek Çayı sistematiği içerisinde T3 seviyesi olarak yorumlanmıştır. Kesit $\sim 1.5$ m yüksekliğinde, laminalı ince silt ve kum ardalanmasından oluşmaktadır (Şekil 6A) ve bu seviyelerden 2 adet OSL örneği alınmıştır. Çekerek Çayı'nın batısında Toklucak Köyü yolu üzerindeki yol yarmasında (TKL), Geldingen formasyonu (Tg) ve taraça seviyesinin dokanağ gözlenmektedir (Şekil 6B). Bu seviye $2 \mathrm{~m}$ kalınlığında ve kanal çakılları ile kum seviyeleri ardalanmasından oluşmaktadır. Kesitin üst kesimleri büyük oranda aşınmıştır. Göreceli konumu +25 m yüksekliğinde olan bu seviyeden 2 OSL örneği alınmıştır. Bektemur kesiti (BKT), 8 metre yüksekliğe sahip, yüksek enerjili bir akarsu fasiyesinde depolanmıştır, kaba taneli (kaba çakıl ve yer yer blok boylu) çökel paketleri arasında yer yer çapraz tabakalı çakıl setleri ve kum barları bulunmaktadır (Şekil 6C). Bu kesitin üst kesimlerinde $+35 \mathrm{~m}$ konumunda yer alan taşkın ovas1 çökelleri içerisinden tarihlendirme örneği alınmıştır.

Yeşilırmak Nehri'nin bütünleşik taraça sistemi ve kronolojisi

Yeşilırmak ve Çekerek akarsularına ilişkin taraça basamaklanmaları, ait oldukları göreceli konumlarına göre sınıflanmıştır. $\mathrm{Bu}$ sınıflandırmanın sonuçları, her iki basamaklanma için üretilen sentetik profilde sunulmaktadır (Şekil 7). Buna göre inceleme alanında 3 farklı basamakta taraça gelişimi bulunmaktadır. T3 taraçasının tabanı gözlenmemekle birlikte tavan yüksekliği +70 metredir. T2 seviyesi hem Çekerek hem de Yeşilırmak basamaklanmasında temel üzerine $+15 \mathrm{~m}$ yüksekliğinde gelmekte ve $20 \mathrm{~m}$ kalınlığa sahiptir. T1 seviyesine ait kesitler sadece Yeşilırmak’ta gözlenmektedir. Çökel kalınlığı 8 metreden fazla olup tavan yüksekliği +15 metredir.

Tanımlanan taraça kesitlerinden elde edilen lüminesans tarihleri Çizelge 1'de sunulmaktadır. OSL yaş analizlerinin hata payları, bu çalışma kapsamında kullanılan 12 tarih için ortalama \%10 olarak hesaplanmıştır. Buna göre T3 seviyesinin depolanması, iki örnek (TRZ 1+2) ile ortalama $72.9 \pm 4.4$ biny1l önce sona ermiştir. Yaklaşı 25 bin y1l süren bir aşınma dönemini takiben T2 seviyesi tabanı TKL 2 ve AKS 2 örneği ile temsil edilmektedir ve taraça depolanmasının en geç $47.75 \pm 3.5$ bin yıl önce başladığını ifade eder. Taraçanın üst seviyesinden elde edilen 2 örnek (SHK 1 ve BKT 1) ise $34.95 \pm 4.7$ biny1l önce aşınmaya başlamıştır. Kızılca kesitinin üst kesimlerinden elde edilen 3 OSL örneğinin yaşları, depolanmanın ortalama $18.5 \pm 2.1$ binyıl önce sona erdiğini ortaya koymaktadır. Kesit kalınlığ 1 göz önünde bulundurulduğunda depolanmanın Son Buzul Maksimum (LGM) dönemi sonunda başladığı ve H1 soğuk/kurak dönemine kadar sürdüğü öngörülebilir. $\mathrm{Bu}$ dönemde eşzamanlı olarak AKS kesitinde T2 seviyesini örten lös çökeli de depolanmıştır. 

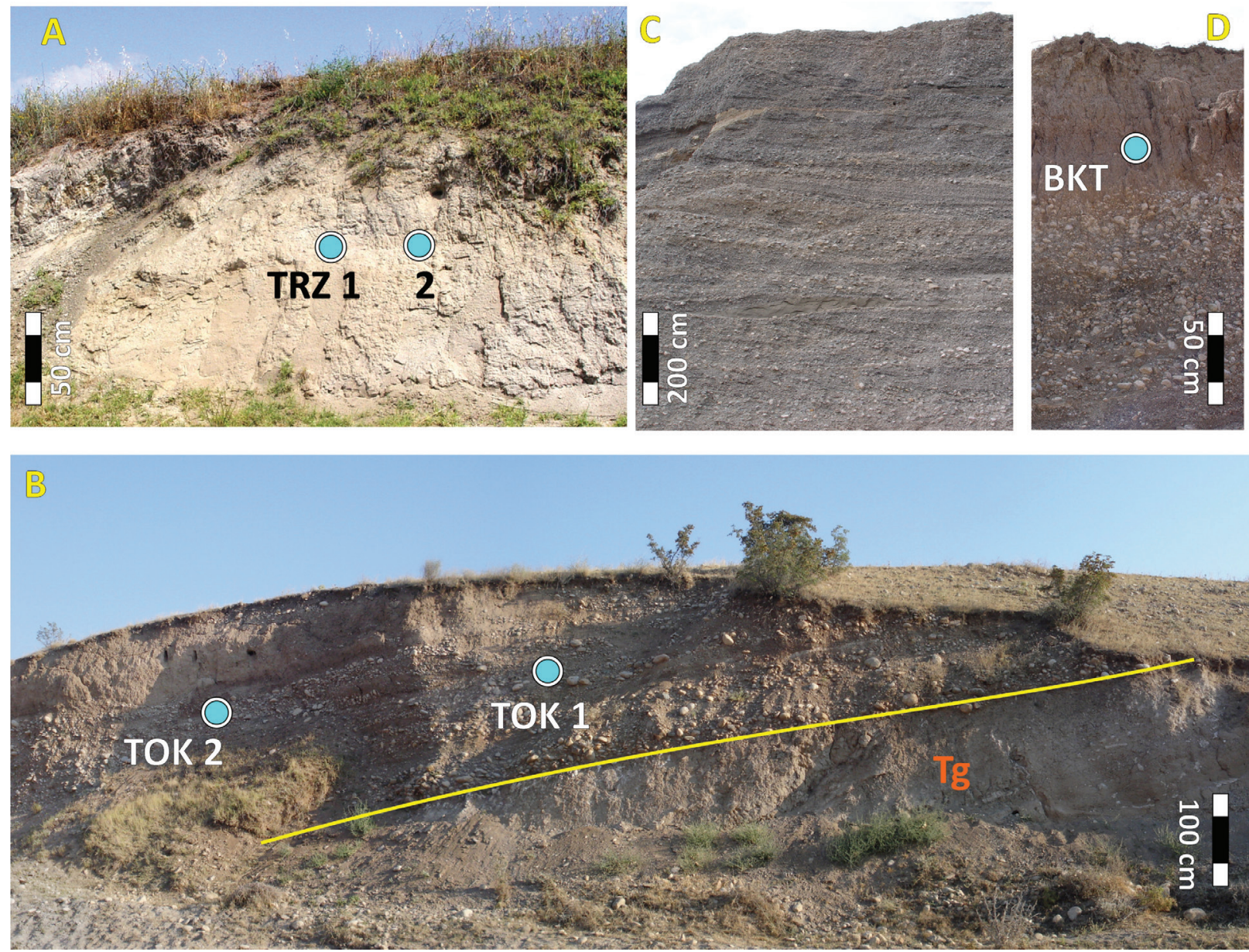

Şekil 6. Çekerek Cayı taraça sisteminin farklı seviyelerinin arazi görünümü. Mavi daireler OSL örnek yerlerine karşılık gelmektedir. A. Terziköy kesitinde T3 seviyesinin tavan kesimine karşılık gelen laminalı siltli çok ince kum, B Toklucak kesitinde T2 taraçasının geç Miyosen-erken Pliyosen yaşlı Geldingen formasyonu ile dokanağı. C. Bektemir kesitinde T2 taraçasının kanal çökelleri, kum barı ara seviyeleri D. Bektemir kesiti üst seviyelerinde taşkın ovası çökelleri ve toprak örtüsü

Figure 6. Field view from different levels of Çekerek River terrace staircases. Blue circles represent OSL sample locations A. Laminated silt and find sand level at top of T3 terrace, the Terziköy section B. The contact between channel gravels of T2 terrace and the Geldingen formation of late Miocene-early Pliocene age at the Toklucak section C. Bedload deposits of T2 terrace intercalated with sand bars at the Bektemur section D. Close-up view of the Bektemur section where channel gravels are overlain by floodplain silt-fine sand and soil 


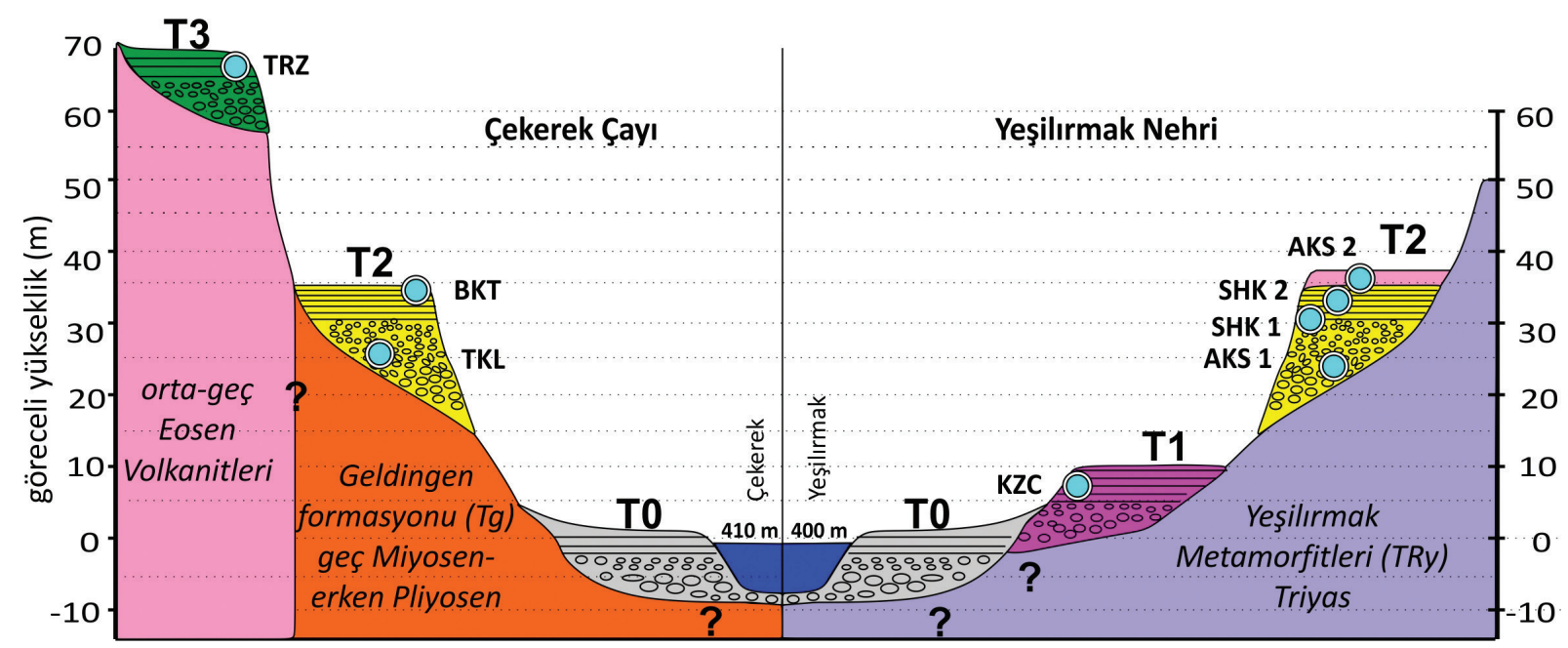

Şekil 7. Yeşilırmak ve Çekerek taraça sisteminin sentetik profilleri. Yükseklikler göreceli olarak akarsuların güncel taşkın ovasından yüksekliğe göre hesaplanmıştır. Mavi daireler OSL örnek yerlerine karşılık gelmektedir.

Figure 7. Synthetic profiles of the Yeşilirmak and Çekerek terrace staircases. Elevations are relative and are calculated based on the recent floodplain of related rivers. Blue circles represents the position of OSL samples.

\section{DEĞERLENDİRME VE TARTIŞMA}

Karasal yar1-kurak iklime sahip bölgelerin, küresel iklimdeyağışvesıcaklığındenetiminde gerçekleşen değişimlere duyarlı olduğu bilinmektedir (Bull, 2008; Faust ve Wolf, 2017). Bu bölgelerde yer alan açık ve kapalı hidrolojik sistemler (ör: göl, akarsu ve mağara) değişimlere belirgin ancak değişen çözünürlükte tepki gösterirler. Sürekli bir sekans oluşturan depolanma sistemlerinde (ör: Göl seviyeleri ve çökelleri ile mağara kayıtları) iklim değişimine yönelik kayıtlar (ör: duraylı izotop oranları ve polen oranı değişimi) yüksek çözünürlük sunarken, akarsu kayıtlarında ise bu cevap, belirgin depolanma ve aşınma dönemleri olarak karşılık bulmaktadır (Blum ve Törnqvist, 2000; Faust ve Wolf, 2017). Depolanma dönemleri, akarsuyun debisinin düştüğü ve çökel taşıma kapasitesinin azaldığı kurak dönemler olarak yorumlanmaktadır. Akarsuyun taşkın ovasını terk ederek yanal ve düşey yönde aşındırdığı dönemler ise yağış rejimi/debi artışına karşılık gelebilir. Bir diğer parametre olan deniz seviyesi değişiklikleri, akarsuyun mutlak kaide seviyesindeki düşmeye bağlı olarak potansiyel enerjisinde artışla ve aşındırmayla, tersi durumda ise depolanmayla sonuçlanabilir (Schumm, 1993). Karadeniz'e $150 \mathrm{~km}$ uzaklıktaki inceleme alanı özelinde, bu değişimlerin etkisinin yakın kıyı bölgelerine göre az olacağı öngörülmüştür. 
Çizelge 1. İnceleme alanındaki taraça sisteminden elde edilmiş lüminesans yaşları (* Kıyak ve Erturaç, 2008; * Erturaç, 2010)

Table 1. Luminescence ages of the terrace staircases (* Klyak and Erturaç, 2008; " Erturaç, 2010)

\begin{tabular}{|c|c|c|c|c|c|c|c|c|}
\hline Kod & Enlem (K) & Boylam (D) & h (m) & $\mathrm{z}(\mathrm{m})$ & $\begin{array}{l}\text { Ölçüm } \\
\text { Sayısı }\end{array}$ & $\begin{array}{l}\text { Eşdeğer Doz, } \\
\text { De (Gray) }\end{array}$ & $\begin{array}{c}\text { Çevresel } \\
\text { Doz Hızı, Dr } \\
\text { (Gray/ka) }\end{array}$ & Yaş (binyıl) \\
\hline AKS-1* & 35.767 & 40.527 & 448 & 2 & 14 & $38.5 \pm 5.6$ & $2.09 \pm 0.02$ & $18.5 \pm 2.7$ \\
\hline AKS-2* & 35.767 & 40.527 & 435 & 15 & 16 & $93.4 \pm 4.2$ & $1.99 \pm 0.02$ & $47.0 \pm 2.2$ \\
\hline SHK-1* & 35.779 & 40.515 & 457 & 2 & 14 & $76 \pm 15$ & $2.15 \pm 0.02$ & $35.2 \pm 6.9$ \\
\hline SHK-2* & 35.781 & 40.513 & 438 & 3 & 12 & $91.3 \pm 09.1$ & $2.10 \pm 0.02$ & $43.4 \pm 4.4$ \\
\hline KZC-1 $^{\#}$ & 35.754 & 40.525 & 422 & 3 & 6 & $39.04 \pm 5.97$ & $2.13 \pm 0.03$ & $18.4 \pm 2.8$ \\
\hline KZC-2 & 35.754 & 40.526 & 422 & 3 & 7 & $39.20 \pm 2.98$ & $2.14 \pm 0.04$ & $18.3 \pm 1.4$ \\
\hline $\mathrm{KZC}^{-3^{\#}}$ & 35.755 & 40.521 & 427 & 2 & 6 & $40.46 \pm 4.44$ & $2.15 \pm 0.04$ & $18.8 \pm 2.1$ \\
\hline TKL-1 $^{\#}$ & 35.597 & 40.518 & 475 & 2 & 8 & $57.94 \pm 4.06$ & $1.27 \pm 0.04$ & $45.7 \pm 3.6$ \\
\hline TKL-2 ${ }^{\#}$ & 35.599 & 40.518 & 459 & 2 & 8 & $61.99 \pm 5.87$ & $1.28 \pm 0.04$ & $48.5 \pm 4.9$ \\
\hline BKT-1* & 35.585 & 40.490 & 459 & 2 & 14 & $44.2 \pm 3.1$ & $1.27 \pm 0.02$ & $34.7 \pm 2.5$ \\
\hline TRZ-1 $^{\#}$ & 35.639 & 40.483 & 528 & 3 & 8 & $91.82 \pm 4.5$ & $1.26 \pm 0.04$ & $73.1 \pm 4.4$ \\
\hline TRZ-2 & 35.639 & 40.483 & 528 & 3.1 & 9 & $91.35 \pm 4.62$ & $1.26 \pm 0.04$ & $72.8 \pm 4.5$ \\
\hline
\end{tabular}

Yeşilırmak bütünleşik taraça sistemi, güncel taşkın ovasının da oluşumu göz önüne alındığında, son buzul devri içerisindeki (son 85 binyıl) dört belirgin aşınma ve depolanma dönemine işaret etmektedir. Buna göre, OSL yaşlarının hata payları da göz önüne alındığında bu çalışmada tarihlendirilebilen depolanma dönemleri MIS 5a, MIS3, MIS2 (LGM) sonu ve Geç Holosen boyunca sürmüştür. $\mathrm{Bu}$ dönemlerin Geç Pleyistosen için tanımlanmış iklim kronolojisi (Denizel İzotop Kayıtları, MIS; Heinrich stadial dönemleri H; Genç Dryas, YD olayı) içerisinde Anadolu ve Doğu Akdeniz'deki geçmiş iklim kayıtları (Şekil 1) ile karşılaştırılması Şekil 8'de sunulmaktadır. Karşılaştırmada kullanılan kayıtlar, kuzey yarımkürede $\left(30^{\circ} \mathrm{K}\right)$ Haziran ayı için hesaplanan güneşlenme değerlerinin değişimi (Berger ve Loutre, 1991), Karadeniz seviye değişiklikleri (Panin ve Popescu, 2007; Yanchilina vd., 2017), Van Gölü seviyesi (Çağatay vd., 2014), Lisan Gölü seviyesi ve belirgin yağış rejimi değişikliği dönemleri (Torfstein vd., 2013), Montecchio Gölü karotunda odunsu türlerin polen oranları değişimi (Allen vd., 1999) ve GB Karadeniz şelfi 25-GC1 karotu (Schumilovskikh vd. 2014) kayıtları; Dim (Ünal-İmer vd., 2015) ve Sofular (Fleitmann vd., 2009) mağaraları $\delta^{13} \mathrm{C}$ sekans kayıtlarıdır. Bunlara ek olarak, Son Buzul Maksimum (LGM) dönemi için Konya Gölü (Fontugne vd., 2009) ve buzul kayıtları (Sarıkaya ve Çiner, 2015) iklim yorumları da karşılaştırmada kullanılmıştır.

İnceleme alanında tanımlanan depolanmalı ve aşınmalı dönemlerin, yerkürenin yörüngesel özelliklerindeki değişimleri uyarınca, kuzey yarım kürede $\left(30^{\circ} \mathrm{K}\right)$ Haziran ayı için hesaplanan güneşlenme değerlerinin değişimi ile belirgin bir korelasyon sunduğu görülmektedir (Şekil 8 A). Benzer bir şekilde taraça gelişimi Van (MIS5a'daki olası zamansal kayma hariç) ve Lisan Göl seviyeleri ve Montecchio Gölü odunsu türler polen oranı değişimi ve GD Karadeniz şelfinde tanımlanan kurak/yağışlı dönemler ile değişen oranlarda eşleşmektedir. Bununla birlikte taraça kayıtlarının, mevcut çözünürlükle, 
buzul dönemleri içerisinde gözlenen kısa süreli soğuk/kurak (stadial) ve 1lıman/yağışlı (interstadial) dönemleri yansitmaktan uzak olduğu görülmektedir.

\section{MIS5a aşınma ve MIS5b Depolanma dönemi}

Yeşilırmak taraça sisteminde T3 seviyesine karşılık gelen MIS5a, günümüzden $72.9 \pm 4.4$ binyıl önceye tarihlendirilmiştir. Başlangıcı tarihlendirilememiş olsa da bu dönemin, bölgede belirgin bir yağışlı dönemin sonrasında başlayan kurak iklim koşullarına karşılık geldiği yorumlanmıştır (Şekil 8A). Van Gölü seviyesinde belirgin bir düşüm öncesindeki yüksek seviyelere karşılık gelen bu dönemin bitişi, Karadeniz seviyesinin MIS4 boyunca süren düşümüne (Şekil $8 \mathrm{C}$ ) karşılık gelmektedir. İtalya Montecchio Gölü polen kayıtlarında MIS5b döneminde \%90 değerlerine ulaşan odunsu türler 77 binyıldan itibaren belirgin olarak azalmış ve $\% 20$ seviyelerine gerilemiştir. Dim mağarası $\delta^{13} \mathrm{C}$ değerlerinde artış gözlenmektedir.

\section{MIS4 aşınma ve MIS3 depolanma dönemi}

Yeşilırmak taraça sistematiğinde en detaylı tarihlendirilen T2 taraça seviyesinin depolanması, MIS4 boyunca ve MIS3 başlangıcına kadar süren uzun bir aşınma dönemi sonrasında, 47 binyıl önce başlamıştır (Şekil 8A). Aşınma döneminin başlangıcı, güneşlenme değerlerinin artışına, Karadeniz seviyesinde belirgin düşmeye, Lisan Gölü kayıtlarında belirgin bir yağışı döneme (Şekil 8B) ve yüksek göl seviyelerine (Şekil 8 D) karşılık gelir. Van Gölü seviyesi ise günümüzdekinden düşüktür ve dönem boyunca ritmik değişkenlik göstermektedir. Güney Karadeniz şelfi MIS4 sonunda bölgede süregelen kurak koşulları yansıtmaktadır ancak MIS3 başlangıcından itibaren yağış11/1lıman dönemleri egemen (Şekil 8 B ve E) olmuştur. Anadolu dağlarında vadi buzullaşmasının bu dönemde başladığı öngörülmektedir (Sarıkaya ve Çiner, 2015)

Depolanma dönemi, MIS3 içerisinde yaklaşık 12 binyıl sürmüştür (Şekil $8 \mathrm{~A}$ ve $8 \mathrm{~B}$ ). Bu dönem Karadeniz seviyesinin günümüz seviyesine yaklaştığı, GD Karadeniz şelfi kayıtlarında ise belirgin bir kurak döneme karş1lık gelmektedir. Van ve Lisan gölleri bu süre zarfinda düşük seviyededir.

\section{MIS3 sonu ve LGM aşınma ile LGM sonrası depolanma dönemi}

Yeşilırmak taraça sisteminde T1 seviyesine karşılık gelen ve ortalama $18.5 \pm 2.1$ binyıl öncesine tarihlendirilen son depolanma dönemi, MIS 3 sonunda başlayıp, LGM boyunca süren belirgin bir aşınma dönemi sonrasında gelişmiştir (Şekil 8A). $\mathrm{Bu}$ depolanma/aşınma dönemleri değerlendirilen geçmiş-iklim verileri ile en yüksek eşleşmeye sahiptir. Aşınma dönemi, küresel olarak soğuk ve kurak ancak Doğu Akdeniz ve Anadolu'da görece yağışlı iklim koşullarına karşılık gelmektedir. Bu aşınma döneminde GD Karadeniz, uzun süren yağışlı bir dönem içerisinde (Şekil 8 B) ancak dış denizlerden bağlantısı kopuk, tatlı su gölü olarak seviyesi günümüze göre -140 m düşüktür (Şekil 8 C). Bu dönemde Lisan Gölü en yüksek seviyeye ulaşmış, Van Gölü seviyesi ise günümüzden yüksekte bulunmaktadır (Şekil 8D). Bu dönemde İç Anadolu'da bulunan diş drenaja kapalı plüvyal göller (ör: Konya Gölü, Fontugne vd., 1999 ve Tuz Gölü, Kashima, 2002) en yüksek seviye ve alansal yayılıma sahiptir. $\mathrm{Bu}$ dönem içinde (21.5-18.5 binyıl) Anadolu vadi buzulları en ileri seviyeye ulaşmıştır. Örneğin, Sandıras Dağ (Batı Toros Dağları; Şekil 1) buzulları, günümüze göre soğuk ancak iki kat yağışlı iklim koşullarını ifade etmektedir (Sarkkaya ve Çiner, 2015). T1 taraçasının depolanma dönemi LGM sonundan H1 stadial dönemine kadar devam etmiştir. Bölgesel olarak, Konya Gölü'nün hızla ortadan kalkması ( 17 biny1l, Fontugne vd., 1999), Tuz Gölü’nün 
daralması ( 17 binyı1; Kashima, 2002). Lisan Gölü seviyesinde $200 \mathrm{~m}$ düşüm (Torfstein vd., 2013) ve Anadolu mağara kayıtlarında $\operatorname{artan} \delta^{13} \mathrm{C}$ değerleri ile ifade olmaktadır. T2 taraçasını örten lös seviyesi ve Kızılca kesitinde gözlenen donmuş kum bloğu bu dönemin son derece kurak ve soğuk olduğunu işaret eden kayıtlardır. İç Anadolu'da Kızılırmak Nehri'nin Nevşehir yakınlarında LGM boyunca devam eden kazılma dönemi sonrasında güncel taşkın ovasının oluşumu da bu dönem içerisinde ( 19 binyıl) başlamaktadır (Doğan, 2010). Bu depolanma döneminin başlangıcı, orta kuzeybatı Anadolu için (Kütahya), günümüzden 14 bin y1l kadar önceye tarihlendirilmektedir (Ocakoğlu vd., 2017).

Geç Buzul-Erken Holosen aşınma dönemi ve güncel taşkın ovasının oluşumu

İnceleme alanında T1 taraçasının aşınması, günümüzden 17-18 binyıl önce 1lıman koşulların ortaya çıkmasıyla başlamıştır, bölgesel olarak önemli ancak kısa süreli YD dönemi flüvyal kayıtta yer almamaktadır. Van Gölü seviyesi bu dönemde günümüz seviyesine yükselmiştir. Bartın Sofular mağarası $\delta^{13} \mathrm{C}$ kaydı (Göktürk vd., 2011) erken Holosen ( 9.36-5.4 binyıl) için yağ $1 S ̧$ rejiminde belirgin bir artışa işaret etmektedir. İnceleme alanında güncel taşkın ovasının (T0) oluşumunun, bu yağışlı (aşınma) dönemin sonunda başladığı öngörülebilir. Geldingen Ovası'nın batısında bulunan ve tarihçesi günümüzden 5.55 binyıl önce başlayan Oluz Höyük (Şekil 3, Dönmez ve Yurtsever-Beyazit, 2016) yerleşimi bu yorumu desteklemektedir. Bununla birlikte Amasya il merkezinde yer alan ve geç Roma dönemine tarihlenen kemerli köprü (Alçakköprü), yapılışından günümüze 3 metre kalınlığında çökelle örtülmüş ve Geç Osmanlı döneminde ek sütunlarla yükseltilmiştir (Erturaç, 2017).

\section{Tektonik yükselme}

$\mathrm{Bu}$ çalışmada elde edilen üç farklı seviyedeki depolanmalı taraçaların terkedilme (aşınma) yaşları ve güncel taşkın ovasından göreceli yükseklikleri ( $\pm 5 \mathrm{~m}$ hata payı ile) Çizelge 2 'de sunulmaktadır. $\mathrm{Bu}$ değerlerin oranlanması ile hesaplanan yükselme/kazılma hızı değerleri yılda 0.81-1.01 mm arasında değişmektedir ve standart sapması 0.09 olarak hesaplanmıştır. Buna göre, inceleme alanında Geç Pleyistosen için sabit yükselme değeri ortalama $0.94 \pm 0.26 \mathrm{~mm} /$ yıl olarak tanımlanabilir. Bu değer, KAF kuzeyi (0.28 mm/yıl, Yıldırım vd., 2013) ve İç Anadolu (0.05-0.06 mm/yı1; Çiner vd., 2015) benzer yaklaşımla elde edilen diğer yükselim hızlarından oldukça yüksektir. Elde ettiğimiz yükselim değerleri, Kuzey Anadolu Fay Zonu'nun (KAFZ) iç bükey sıkışmalı bir büklüm yaptığı kesim için bölgesel (1) ya da Ezinepazar Fayı'nın geometrisi içerisinde yerel sıkışma ya da Geldingen Ovası için çökme hızına (2) karşılık geldiği yönünde değerlendirilebilir. İlk hipotezin test edilmesi için alansal olarak dağılmış yeni veri setlerine ihtiyaç duyulmaktadır. İkinci hipotez doğru kabul edildiği takdirde ovanın (200 m çökel kalınlığ göz önüne alınarak) oluşum yaş1 200-250 bin y1l öncesine tarihlenebilir. Bu yorum Erturaç ve Tüysüz (2012) tarafindan önerilen Ezinepazar Fay Zonu'nun gelişim ve batıya doğru ilerleme zamanlamasıyla uyumludur. 


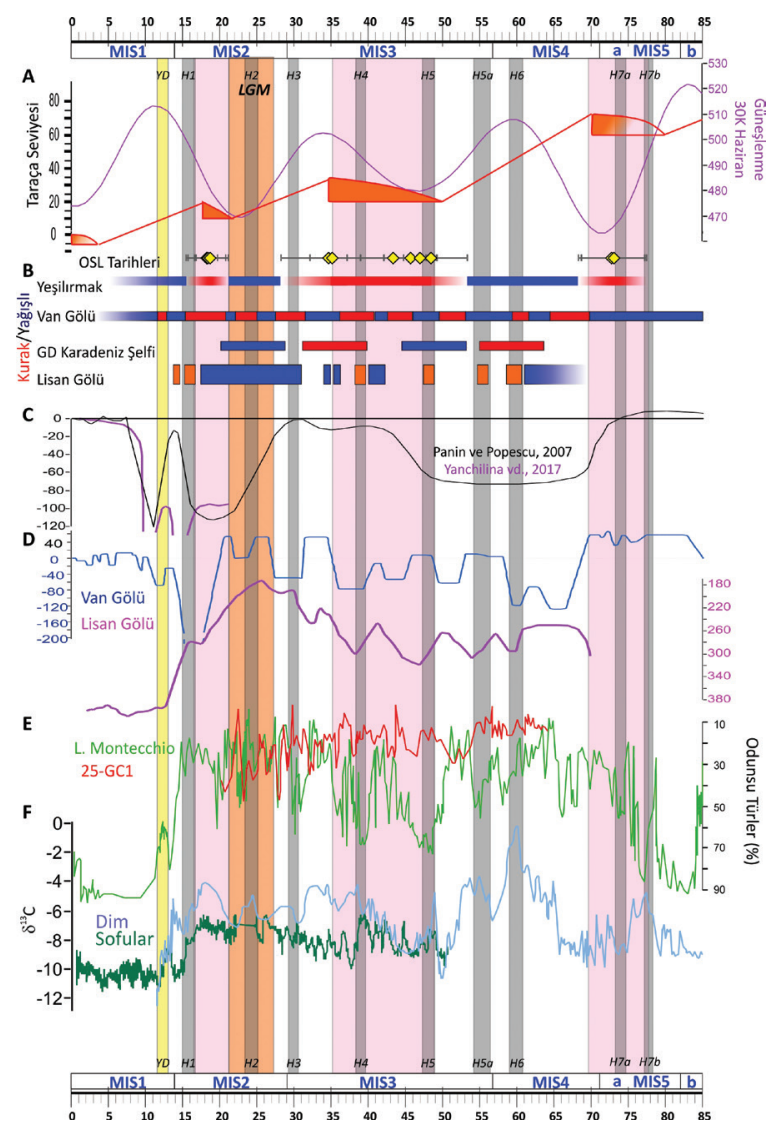

Şekil 8. Son Buzul Çağı süresince ( 85 binyıl-günümüz) Yeşilırmak-Çekerek taraça sisteminin iklim ve deniz seviyesi kayıtları ile karşılaştırması. A. Bütünleşik taraça sisteminin göreceli pozisyonları, OSL yaşları ve depolanma dönemleri ile 30K Haziran ayı güneşlenme değerleri (Berger ve Loutre, 1991), B. Yeşilırmak (bu çalışma) Van Gölü (Çağatay vd., 2014); GD Karadeniz Şelfi (25 GC-1; Schumilovskikh vd., 2014) ve Lisan Gölü (Torfstein vd., 2013) tanımlanmış kurak/yă̆ışlı dönemler, C. Karadeniz seviye değişiklikleri (Panin ve Popescu, 2007; Yanchilina vd., 2017); D. Van (Çağatay vd., 2014) ve Lisan (Ürdün, Torfstein vd., 2013) Göl seviyesi değişiklikleri, E. Montecchio Gölü (İtalya) ve GD Karadeniz Şelfi (25 GC-1; Schumilovskikh vd., 2014) sondaj karotlarından elde edilen odunsu türlerine ait polenlerin \% değişimi grafikleri F. Dim (Ünal-İmer vd., 2015) ve Sofular (Fleitmann vd., 2009) sarkit/dikit kayıtlarında $\delta^{13} \mathrm{C}$ değişimi. Kısaltmalar: MIS: Denizel izotop katları, LGM: Son Buzul Maksimum; YD. Genç Dryas; H: Heinrich kurak/soğuk dönemlerini ifade etmektedir.

Figure 8. Comparison of the Yeşilırmak-Çekerek terrace staircases with the climate and sea level records since the last $85 \mathrm{ka}$ A. OSL ages, relative positions of integrated terrace staircases and $30 N$ June insolation values (Berger and Loutre, 1991), B. Humid vs. Dry periods inferred from the Yeşillrmak terraces (this study), Lake Van (Çağatay et al., 2014); SE Black Sea shelf (25 GC-1; Schumilovskikh et al., 2014) and Lake Lisan (Torfstein et al., 2013), C. Black Sea level changes (Panin and Popescu, 2007; Yanchilina et al., 2017); D. Lake level variations at Lake Van (Çağatay et al., 2014) and Lisan (Jordan, Torfstein et al., 2013) $E$. Change in \% values of pollen of woody taxa for Lake Montecchio (Italy) and SE Black Sea Shelf (25 GC1; Schumilovskikh et al., 2014) cores, $F$. $\delta^{13} C$ record of stalagmites from Dim (Ünal-Imer et al., 2015) and Sofular (Fleitmann et al., 2009) caves. Abbrevations: MIS: Marine Isotope Stage, LGM: Last Glacial Maximum; YD. Younger Dryas; H: Heinrich stadials.

\section{ÖNERILLER}

$\mathrm{Bu}$ çalışmada elde edilen taraça konum ve yaşlandırma verileri, İç Anadolu'nun kuzey kesimi için Son Buzul Devrinde gerçekleşen önemli hidrolojik (iklim) değişimlere ve düşey yönlü deformasyona yönelik bir yaklaşım sunmaktadır. Bölgede gözlem, ölçüm ve tarihlendirme hassasiyetinin arttırılması, bölgesel karşılaştırmalar ile daha hassas yorumlara gidilmesini sağlayacaktır.

\section{KATKI BELİRTME}

Bu çalışma, ilk yazarın doktora çalışması süresince elde edilen arazi ve tarihlendirme verilerinin yeniden yorumlanması ile üretilmiştir. İlk yazar, arazi çalışmasındaki desteklerinden ötürü Amasya Valiliği, Yeşilırmak Kalkınma Birliği, ADK kurucu üyeleri Aydın Babacan ve Hasan Varış’a teşekkürü bir borç bilir. Çalışmanın bilimsel yaklaşımı, Catherine Kuzucuoğlu ve Zeki Bora Ön ile yapılan tartışmaların yanısıra; makaleyi titizlikle değerlendiren Faruk Ocakoğlu ve Serkan Üner'in değerli öneri ve katkılarıyla ilerlemiştir. 
Çizelge 2. Taraça yaş ve konum verileri ile yıllık yükselme hızı

Table 2. Uplift rates calculated using terrace positions and ages

\begin{tabular}{|c|c|c|c|c|c|c|c|c|c|c|c|}
\hline \multirow{2}{*}{$\begin{array}{c}\text { Örnek } \\
\text { BKT-1 }\end{array}$} & \multirow{2}{*}{$\begin{array}{l}\text { Taraça } \\
\text { Çekerek }\end{array}$} & \multirow{2}{*}{$\begin{array}{l}\text { Seviye } \\
\mathrm{T} 2\end{array}$} & \multicolumn{3}{|c|}{$\begin{array}{c}\text { Yaş } \\
\text { (binyll) }\end{array}$} & \multicolumn{3}{|c|}{$\begin{array}{l}\text { Göreceli Yükseklik } \\
\text { (m) }\end{array}$} & \multicolumn{3}{|c|}{$\begin{array}{l}\text { Yükselme Hızı } \\
\text { (mm/yıl) }\end{array}$} \\
\hline & & & 34.7 & \pm & 2.5 & 35 & \pm & 5 & 1.01 & \pm & 0.22 \\
\hline TRZ-1-2 & Çekerek & T3 & 72.9 & \pm & 4.4 & 70 & \pm & 5 & 0.96 & \pm & 0.13 \\
\hline KZC-1-2-3 & Yeşilırmak & $\mathrm{T} 1$ & 18.5 & \pm & 2.1 & 15 & \pm & 5 & 0.81 & \pm & 0.36 \\
\hline \multirow[t]{3}{*}{ SHK-1 } & Yeşilırmak & $\mathrm{T} 2$ & 35.2 & \pm & 6.3 & 35 & \pm & 5 & 0.99 & \pm & 0.32 \\
\hline & & & & & & \multicolumn{3}{|c|}{ ORTALAMA } & 0.94 & \pm & 0.26 \\
\hline & & & & & & \multicolumn{3}{|c|}{ STD } & \multicolumn{3}{|c|}{0.09} \\
\hline
\end{tabular}

\section{EXTENDED SUMMARY}

River terraces are remnants of former river floodplains that are fossilized above present-day river channels, often in staircase systems (Erinç, 1982; Bull, 2008; Pazzaglia, 2013). The formation of terrace staircases is attributed to both tectonic uplift (e.g. Bridgland, 2000, Lave' and Avouac, 2001; Bridgland and Westaway, 2008; Demoulin et al., 2017), climate and sea/base level changes (e.g. Schumm, 1993; Blum and Törnqvist, 2000; Vanderberghe, 2002, 2003; Macklin et al., 2012; Faust and Wolf, 2017). Variations in tectonic and climatic conditions cause perturbations in the fluvial system, which, over time, lead to widening of valley floors, subsequent aggradation and incision, thereby producing terraces (Pazzaglia, 2013), representing the complex response of the fluvial system to the variables listed above (Bull, 2008). River incision creates terrace risers and isolates each terrace step, thus making terraces more evident in the landscape and form valuable archives when their chronostratigraphical frameworks can be reconstructed (e.g. Wallinga, 2002; Rixhon et al., 2017). Under certain tectonic environments, these steps can be even more distinct and be used to calculate the rate of vertical deformation (eg. Olzsak, 2017). The mechanisms of terrace staircase formation, or contribution and interaction of each variable is still under debate (cf. Faust and Wolf, 2017) but they have potential to provide data on major shifts in the earth system especially on regional settings.
This paper reports on data achieved from the terrace staircases formed at lower reaches of Yeşilirmak (Iris) River, south of the Geldingen Plain, Central North Anatolia (Figure 1). A welldeveloped three step terrace systematic, located at max $+70 m$ (above today's recent floodplain), is investigated with mapping surveys and the chronology is established by using luminescence (OSL) dating. Precise relative positions and ages of the initiation and termination of depositional periods led us to enhance our understanding of the fluvial response (duration of major erosional and depositional periods) to regional climate since the last $\sim 85 \pm 5 \mathrm{ka}$ to recent. We correlated our findings with insolation curve for N30 June (Berger and Loutre, 1991) and with several paleo-climatic archives of Anatolia and central to eastern Mediterranean such as changes in Black Sea levels (Panin and Popescu, 2007; Yanchilina et al., 2017), environmental and level changes in Van (Çăgatay et al., 2014), Konya (Fontugne et al., 1999) and Lisan (Torfstein et al., 2013) lakes, stable isotope $\left(\delta^{13} C\right)$ variations in two stalagmite records located to the south and north of Anatolia; Dim (Ünal-Imer et al., 2015) and Sofular (Fleitmann et al., 2009) caves, glacier records of Anatolian mountains (Sarlkaya and Çiner, 2015), variations in arboreal pollen from Montecchio Lake (Allen et al., 2009) and Black Sea core 25 GC1 (Schumilovskikh et al., 2014) in order to test our chronology and climatic interpretations (see Figure 1 for locations and Figure 8 for correlation graph). 
The study area is located at the center of one of the biggest river systems of northern Anatolia, Yeşilırmak (Iris) River $\sim 150 \mathrm{~km}$ to the south of Black Sea. The terrace staircases are adjacent to Geldingen Plain ( 380 amsl), which is formed under acute geometrical relationships between Ezinepazar and Sungurlu faults, synthetic splays of North Anatolian Fault (Figure 2, Barka and Kadinsky-Cade, 1988; Erturaç and Tüysüz, 2012). Geldingen Plain, also acts as a joining site of the two major tributaries of river system, Yessilırmak and Çekerek-Çorum Rivers draining $6300 \mathrm{~km}^{2}$ and $11700 \mathrm{~km}^{2}$ area respectively within a region classified as semi-arid steppe climate (Türkeş, 1996). We have calculated the total mean annual precipitation of the drainage basins as $1475 \mathrm{~mm} /$ yr by using precipitation grid data from Ustaoğlu (2011). Within this climatic setting, the mean annual discharge of the Yeşilirmak River System is $65.4 \mathrm{~m}^{3} / \mathrm{s}$, carrying $\sim 2.9$ million tons of suspended sediment to Black Sea, measured at Durucasu Station (EIE, 2000).

We mapped the terrace staircases in detail, measured positions of the contact with the basement and the terrace risers using handheld GPS accompanied with standard topographical maps and $10 \mathrm{~m}$ resolution DEM with $\pm 5 \mathrm{~m}$ accuracy. The sections are carefully examined for facies classification where we sampled low energy, fine grained layers for optically stimulated luminescence (OSL) dating. Here we represent 12 OSL ages (Table 1) from the terrace staircases which were previously reported by Klyak and Erturaç (2008) and Erturaç (2010) where the laboratory procedures and measurement techniques of dating are detailed in Klyak and Erturaç (2008).

We identified three depositional steps along the gorges of Yeşilirmak (Figure 5) and Çekerek Rivers (Figure 6). The position and geometry of these steps are represented with a joint synthetic profile (Figure 7). OSL dating reveals that these terrace steps, namely T3 (+70 m), T2 (+35 m) and $T 1(+15)$ are deposited during MIS5a, MIS3, late LGM and eroded during the time periods in between (Figure 7). The terrace deposition (erosion) can be correlated with decreasing (increasing) values of insolation (Figure 8A). Especially the intense erosional (humid) LGM period is also clearly evident in adjacent paleoclimate archives (Figure 8). Despite a significant drop in Black Sea Level (Panin and Popescu, 2007), there is an apparent rise in lake levels (Lake Van; Çăgatay et al., 2014; Lake Lisan, Torfstein et al., 2013; Lake Konya; Fontugne et al., 1999) and glaciers in Anatolian mountains advancing to their maximum (Sarlkaya and Çiner, 2015). Post-LGM, the region witnessed a severely cold and dry period, at ca.18.5 $2.1 \mathrm{ka}$, which is evident in fluvial architecture of $T 1$ and also with a $2 \mathrm{~m}$ thick loess deposit overlying the T2 terrace (Figure $5 \mathrm{~B}$ and D). It is well known that the extensive ephemeral lakes of LGM (Konya and Lisan) could not recover from this dry period.

To conclude, we claim that (1) terrace formation is related with major climatic shifts affecting the hydrological system of the river (2) our age constraints yield comparable and consistent results with adjacent paleoclimatic archives of eastern Mediterranean region.

Relative positions of the terrace risers and abandonment ages for each terrace, enables us to calculate a long-term vertical deformation at the study area, located to the south of the North Anatolian Fault, uplifting at a constant rate of $0.94 \pm 0.26 \mathrm{~mm} /$ year with 0.09 standard deviation (Table 2). This deformation can be either local, related with the geometry of active faults, or express a regional uplift rate for the southern block of the North Anatolian Fault Zone at its wide convex bend. Each hypothesis should be tested by extending our data geographically and temporally from adjacent terrace systematics. 


\section{ORCID}

M. Korhan Erturaç (D) https://orcid.org/0000-0002-6501-760X

Nafiye Güneç Klyak D https://orcid.org/0000-0002-5429-2825

\section{DEĞİNILEN BELGELER}

Aitken, M.J., 1998. An Introduction to Optical Dating: The Dating of Quaternary Sediments by the Use of Photon-Stimulated Luminescence. Oxford University Press, New York, 267

Allen, J.R., Brandt, U., Brauer, A., Hubberten, H.W., Huntley, B., Keller, J., Kraml, M., Mackensen, A., Mingram, J., Negendank, J.F. and Nowaczyk, N.R., 1999. Rapid environmental changes in southern Europe during the last glacial period. Nature, 400(6746),740-743.

Antoine, P., Lautridou, J.-P. and Laurent, M., 2000. Long-term fluvial archives in NW France: response of the Seine and Somme rivers to tectonic movements, climatic variations and sealevel changes. Geomorphology, 33: 183-207.

Barka A.A. and Kadinsky-Cade, K. 1988. Strike-slip fault geometry in Turkey and its influence on earthquake activity. Tectonics 7, 663-684.

Berger A. and Loutre M.F., 1991, Insolation values for the climate of the last 10 million of years. Quaternary Sciences Review, Vol. 10 No. 4 pp. 297-317.

Blum, M.D., Törnqvist, T.E., 2000. Fluvial responses to climate and sea-level change: a review and look forward. Sedimentology 47, 2-48.

Bridgland, D.R., 2000. River terrace systems in northwest Europe: an archive of environmental change, uplift and early human occupation. Quat. Sci. Rev. 19, 1293-1303.

Bridgland, D.R., Westaway, R., 2008. Climatically controlled river terrace staircases: a worldwide Quaternary phenomenon. Geomorphology 98, 286-315.

Bull, W.B., 2008. Geomorphic Response to Climate Change, 326 pages. The Blackburn press.

Burbank, D.W.,Leland,J.,Fielding,E.,Anderson,R.S.,Br ozovic,N.,Reid,M.R., Duncan, C., 1996. Bedrock incision, rock uplift and threshold hill slopes in the northwestern Himalayas. Nature 379,505-510.

Çağatay, M.N., Öğretmen, N., Damcı, E., Stockhecke, M., Sancar, Ü., Eriş, K.K. and Özeren, S., 2014.
Lake level and climate records of the last 90ka from the Northern Basin of Lake Van, eastern Turkey. Quaternary Science Reviews, 104, 97116.

Çiner, A., Doğan, U., Yıldırım, C., Akçar, N., IvyOchs, S., Alfimov, V., Kubik, P.W. and Schlüchter, C., 2015. Quaternary uplift rates of the Central Anatolian Plateau, Turkey: insights from cosmogenic isochron-burial nuclide dating of the Kizılırmak River terraces. Quaternary Science Reviews, 107: 81-97.

Demoulin, A., Mather, A., Whittaker, A., F, 2017. Fluvial archives, a valuable record of vertical crustal deformation. Quaternary Science Reviews, $166,10-37$.

Doğan, U., 2010. Fluvial response to climate change during and after the Last Glacial Maximum in Central Anatolia, Turkey. Quaternary International, 222, 221-229.

Doğan, U., 2011. Climate-controlled river terrace formation in the Kizilırmak Valley, Cappadocia section, Turkey: inferred from Ar-Ar dating of Quaternary basalts and terraces stratigraphy. Geomorphology, 126, 66-81.

Dönmez, Ş. ve Yurtsever-Beyazıt, A., 2016. Oluz Höyük Kazısı Dokuzuncu Dönem (2015) Çalışmaları: Değerlendirmeler ve Sonuçlar. 38. Kazı Sonuçları Toplantısı, T.C. Kültür ve Turizm Bakanlığ1 Yayın No: 3490, 3. Cilt, 537-552.

Duller, G.A.T., 2008. Luminescence Dating: Guidelines on Using Luminescence Dating in Archaeology. English Heritage, Swindon.

EIE, 2000. Türkiye Akarsularında Süspanse Sediment Gözlemleri ve Sediment Taşınım Miktarı. Elektrik İşleri Genel Müdürlüğü, Özel Sayı 20/17, Ankara.

Elias, A.S., (ed), 2007. Encyclopedia of Quaternary Science, Elsiever Ltd. Publications, ISBN: 978-0444-52747.

Erinç, S., 1982. Jeomorfoloji 1. Genişletilmiş 2. bask1, , 2931. 736 sf., İstanbul Üniversitesi, Edebiyat Fakültesi Yayınları, 736 sf.

Erturaç, M.K., 2017. Landscape Evolution and Occupation History in the Vicinity of Amasya. Artical 22 in Landscapes and Landforms of Turkey, Eds: Catherine Kuzucuoğlu, Atilla Çiner, Nizamettin Kazanc1, Springer.

Erturaç, M.K., 2010. Amasya ve Çevresinin Morfotektonik Evrimi (yayınlanmamış doktora tezi), İTÜ Avrasya Yer Bilimleri Enstitüsü). 
Erturaç, M. K., ve Tüysüz, O., 2012. "Kinematics and basin formation along the Ezinepazar-Sungurlu fault zone, NE Anatolia, Turkey." Turkish Journal of Earth Sciences, 21, 4, 497-520.

Faust, D. and Wolf, D., 2017. Interpreting drivers of change in fluvial archives of the Western Mediterranean-A critical view. Earth-Science Reviews. 53-83. 10.1016/j.earscirev.2017.09.011.

Fleitmann, D., Cheng, H., Badertscher, S., Edwards, R.L., Mudelsee, M., Göktürk, O.M., Fankhauser, A., Pickering, R., Raible, C.C., Matter, A., Kramers, J., Tuysuz, O., 2009. Timing and climatic impact of Greenland interstadials recorded in stalagmites from northern Turkey. Geophys. Res. Lett. 36, L19707.

Fontugne, M., Kuzucuoğlu, C., Karabiyikoğlu, M., Hatte, C. and Pastre, J.F., 1999. From Pleniglacial to Holocene: a $14 \mathrm{C}$ chronostratigraphy of environmental changes in the Konya Plain, Turkey. Quaternary Science Reviews, 18, 573-591.

Forman, S.L., 2015. Luminescence Dating in Paleoseismology. In Beer, M., Kougioumtzoglou, I.A., Patelli, E., Au, I.S.-K. (Eds.) Encyclopedia of Earthquake Engineering, Springer.

Galbraith, R.F. and Roberts, R.G. 2012. Statistical aspects of equivalent dose and error calculation and display in OSL dating: an overview and some recommendations. Quaternary Geochronology 11, $1-27$.

Göktürk O.M., Fleitmann D, Badertscher S., Cheng, H., Edwards, RL., Leuenberger, M., Frankhauser, A., Tüysüz, O., Kramers, J., 2011. Climate on the southern Black Sea coast during the Holocene: Implications from the Sofular Cave record. Quaternary Science Reviews 30: 2433-2445.

Karaalioğlu, B. 1983. Geldingen Ovasının Hidrojeolojik Etüdü, Devlet Su İşleri Genel Müdürlüğü, Ankara.

Kıyak, N. and Erturaç, M., 2008. Luminescence ages of feldspar contaminated quartz from fluvial terrace sediments. Geochronometria, 30, 55-60.

Kashima, K., 2002. Environmental and climatic changes during the last 20,000 years at Lake Tuz, central Turkey. Catena 48, 3-20.

Lave, J. and Avouac, J.P., 2001. Fluvial incision and tectonic uplift across the Himalayas of Central Nepal. Journal of Geophysical Research, 106(B11): 26,561-26,591.
Macklin, M.G., Lewin, J., Woodward, J.C., 2012. The fluvial record of climate change. Phil. Trans. R. Soc. A 370, 2143-2172.

Maddy, D., Veldkamp, A., Demir, T., van Gorp, W., Wijbrans, J.R., van Hinsbergen, D.J.J., Dekkers, M.J., Scahreve, D., Schoorl, J.M., Scaife, R., Stemerdink, C., van der Schriek, T., Bridgland, D.R., Aytaç, A.S., 2017. The Gediz River fluvial archive: A benchmark for Quaternary research in Western Anatolia. Quat. Sci. Rev. 166, 68-75.

Murray, A.S. and Wintle, A.G. 2003 The single aliquot regenerative dose protocol: potential for improvements in reliability. Radiation Measurements, 37, 377-381.

Ocakoğlu, F., Potoğlu-Erkaya, İ., Çilingiroğlu, Ç., Dinçer, B., Unan, S., 2017. Kureyşler (Kütahya Batıs1) Bölgesinin Paleoklimatolojik İncelemesi ve Höyüktepe Höyüğü Arkeolojisi ile İlişkisi. Eskişehir Osmangazi Üniversitesi Araştırma Fonu Projesi.74 s.

Olszak, J., 2017. Climatically controlled terrace staircases in uplifting mountainous areas. Global and Planetary Change, 156, 13-23.

Pan, B., Burbank, D., Wang, Y., Wu, G., Li, J., Guan, Q.,2003. A 900 k.y. record of strath terrace formation during glacial-interglacial transitionsin Northwest China. Geology 31, 957-960.

Panin, N. and Popescu, I., 2007. The northwestern Black Sea: climatic and sea-level changes in the Late Quaternary. The Black Sea Flood Question: Changes in Coastline, Climate and Human Settlement. Springer, Dordrecht, 387-405.

Pazzaglia, F.J., 2013. Fluvial Terraces. In: J.F. Shroder (Editor), Treatise on Geomorphology. Vol:9.22, Academic Press, San Diego, pp. 379-412.

Rhodes, E.J., 2011. Optically Stimulated Luminescence Dating of Sediments over the Past 200,000 Years. Annual Review of Earth and Planetary Sciences, 39: 461-488.

Rixhon, G., Briant, R.M., Cordier, S., Duval, M., Jones, A. and Scholz, D., 2017. Revealing the pace of river landscape evolution during the Quaternary: recent developments in numerical dating methods. Quaternary Science Reviews, 166, 91-113.

Ryan, W.B., Carbotte, S.M., Coplan, J.O., O’Hara, S., Melkonian, A., Arko, R., Weissel, R.A., Ferrini, V., Goodwillie, A., Nitsche, F. and Bonczkowski, J., 2009. Global multi resolution 
topography synthesis. Geochemistry, Geophysics, Geosystems, 10.

Sarıkaya, M.A. ve Çiner, A., 2015. Türkiye Geç Pleyistosen Buzullaşması ve Paleoiklimi. Maden Tetkik ve Arama Dergisi, 151, 111-132.

Schumilovskikh, L.S., Fleitmann, D., Nowaczyk, N.R., Behling, H., Marret, F., Wegwerth, A. and Arz, H.W., 2014. Orbital and millenial-scale environmental changes between 64 and $25 \mathrm{ka} \mathrm{BP}$ recorded in Black Sea sediments. Climate of the Past, 10, 939-945.

Schumm, S.A., 1993. River response to base level change: implications for sequence stratigraphy. J. Geol. 101, 279-294.

Torfstein, A., Goldstein, S.L., Stein, M. and Enzel, Y., 2013. Impacts of abrupt climate changes in the Levant from Last Glacial Dead Sea levels. Quaternary Science Reviews, 69, 1-7.

Türkes, M., 1996. Spatial and temporal analysis of annual rainfall variations in Turkey. Int. J. Climatol. 16, 1057-1076.

Tüysüz, O. 1992. Çorum G-35-c ve G-35-d paftalarının 1/50.000 ölçekli jeoloji haritaları. TPAO harita serisi (yayınlamamış).

Tüysüz, O. 1996. Amasya ve çevresinin jeolojisi. Türkiye 11. Petrol Kongresi, Ankara. 32-48.

Ustaoğlu, B., 2011. Türkiye'de A2 Emisyon Senaryosuna Göre Ortalama Yağış Tutarlarının Olas1 Değişimi, (2010-2099). Fiziki Coğrafya Araştırmaları Sistematik ve Bölgesel. Prof. Dr. M.Y. Hoşgören'e Armağan Kitabı, sf. 473- 484, Türk Coğrafya Kurumu Yayınları. ISBN:978-9756686-03-4.
Ünal-İmer, E., Shulmeister, J., Zhao, J.X., Uysal, I.T., Feng, Y.X., Nguyen, A.D. and Yüce, G., 2015. An 80 kyr-long continuous speleothem record from Dim Cave, SW Turkey with paleoclimatic implications for the Eastern Mediterranean. Scientific reports, 5, 13560.

Vandenberghe, J., 2002. The relation between climate and river processes, landforms and deposits during the Quaternary. Quat. Int. 91, 17-23.

Vandenberghe, J., 2003. Climate forcing of fluvial system development: an evolution of ideas. Quat. Sci. Rev. 22, 2053-2060

Vandenberghe, J., 2008. The fluvial cycle at coldwarm-cold transitions in lowland regions: A refinement of theory, Geomorphology, 98, 3-4, 275-284.

Wallinga, J., 2002. Optically stimulated luminescence dating of fluvial deposits: a review. Boreas 31, 303-322.

Yanchilina, A.G., Ryan, W.B., McManus, J.F., Dimitrov, P., Dimitrov, D., Slavova, K. and Filipova-Marinova, M., 2017. Compilation of geophysical, geochronological, and geochemical evidence indicates a rapid Mediterraneanderived submergence of the Black Sea's shelf and subsequent substantial salinification in the early Holocene. Marine Geology, 383, 14-34.

Yıldırım, C., Schildgen, T., Echtler, H., Melnick, D., Strecker, M.R., Bookhagen, B., Çiner, A., Niederman, S., Merchel, S., Martschini, M. and Steier, P., 2013. Tectonic implications of fluvial incision and pediment deformation at the northern margin of the Central Anatolian Plateau based on multiple cosmogenic nuclides. Tectonics 32, 1-14. 